
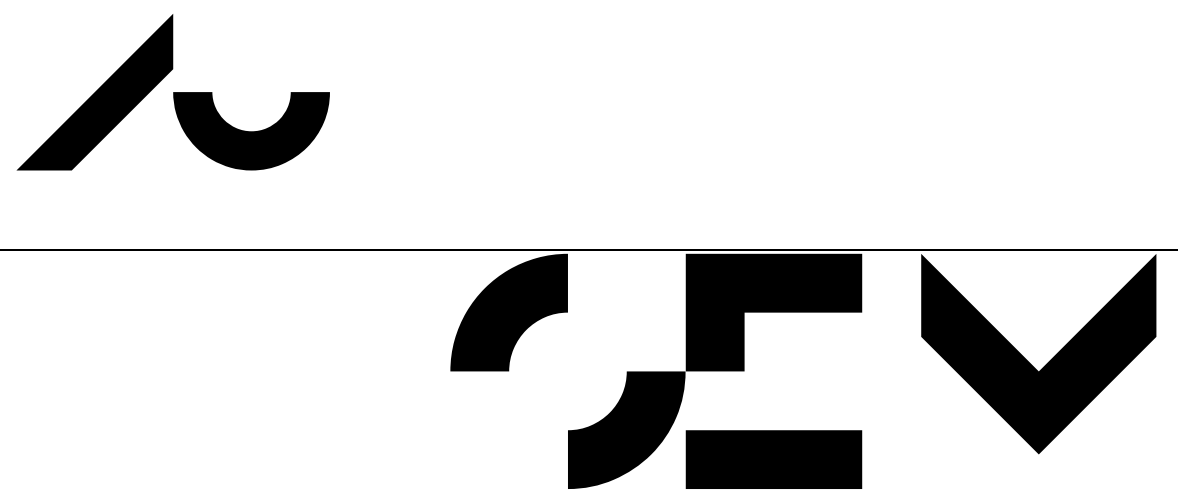

Economics Working Paper

2010-12

\title{
On Utilization and Stockpiling of Prescription Drugs when Co-payments Increase: Heterogeneity across Types of Drugs
}

Niels Skipper 

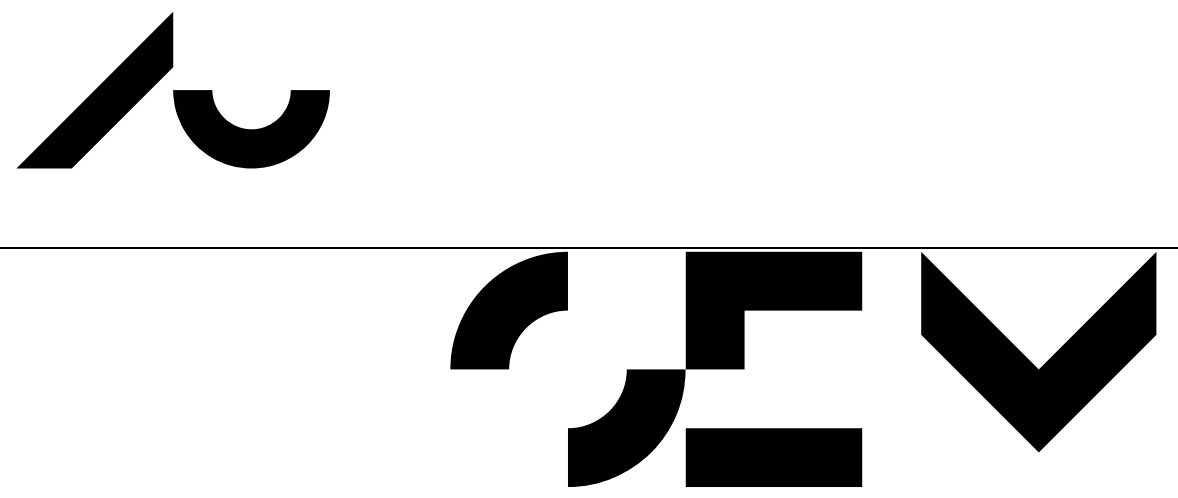

\section{Economics Working Paper}

2010-12

School of Economics and Management

Aarhus University

Bartholins Allé 10, Building 1322

DK-8000 Aarhus C - Denmark

Phone +4589421610

Mail: oekonomi@econ.au.dk

Web: www.econ.au.dk 


\title{
On Utilization and Stockpiling of Prescription Drugs when Co-payments Increase: \\ Heterogeneity across Types of Drugs
}

\author{
July 2010 \\ Niels Skipper \\ School of Economics \\ and Management \\ Aarhus University
}

\begin{abstract}
:
This paper investigates prescription drug utilization changes following an exogenous shift in consumer co-payment caused by a reform in the Danish subsidy scheme for the general public. Two different types of medication are considered - insulin for treatment of the chronic condition diabetes and penicillin for treatment of non-chronic conditions. Using purchasing records for a $20 \%$ random sample of the Danish population, I show that increasing co-payments lower the utilization of both drugs. I demonstrate that individuals treated with drugs for chronic conditions react to the policy change by stockpiling on their medications. This has implications for other papers in the literature that use variation in subsidy rates over time to estimate the price elasticity of demand. This is not the case for penicillin however, where price elasticities are estimated to be in the $-.18--.35$ range. Further, I find that the lower part of the income distribution is more price responsive.
\end{abstract}

Key words: Prescription drugs, co-payments, price elasticities, stockpiling.

JEL codes: I11, I18

Acknowledgements: I greatly appreciate helpful comments and suggestions from Søren LethPetersen, Marianne Simonsen, Lars Skipper, Michael Svarer and Rune Vejlin, as well as participants at the 2009 iHEA conference. 


\section{Introduction}

Health care expenditures have been growing rapidly in the OECD countries over the last years, with an OECD average of $7.2 \%$ of GDP in 2000 and $8.9 \%$ of GDP in 2006, and are foreseen to do so in the future as well. A large contributor to this increase is prescription drug expenditures. In countries where health care is universally financed (and sometimes even supplied) by the government, including e.g. Denmark where average drug expenditures went up 30.6\% from 1995-2003, different cost containment strategies have been employed to deal with increased prescription drug expenditures, for example by increasing the consumer co-payment.

This paper investigates how changes in consumer co-payment affect utilization and prices of prescription drugs in Denmark while exploiting a reform of the general population reimbursement scheme for prescription drugs. As opposed to many papers in the literature, I have access to individual level data which allows me to control for different characteristics determining purchase decisions. The data are drawn from Danish administrative registers and hold information on a $20 \%$ random sample of the Danish population. The data include daily information on prescription drug purchases such as type of drug, quantity, price, and co-payment. In addition, I have information about socioeconomic status that allows me to study effects over different sub-groups of the population within the same institutional regime.

In Denmark, the scheme by which consumers are subsidized by the government was changed dramatically in 2000 in terms of consumer co-payments. Before 2000, the Danish population faced a subsidy scheme that offered first dollar coverage for drugs ${ }^{1}$. The drugs were divided into two categories, Type A and Type B drugs. Type A had a 50\% subsidy and Type B a 75\% subsidy. Insulin had a special status as the only product with a co-payment of $0 \%$. From March 12000 , this system was replaced by a reimbursement scheme by which co-payments became a function of individual level consumption; see Simonsen et al. (2010). One of the main goals of this reform was to increase the average consumer co-payment while retaining a safety net for patients with a catastrophic level of expenditures.

I evaluate the effects of the policy change using a regression discontinuity design that makes use of exact dates of purchases. My contribution, relative to other studies that rely on time variation to

\footnotetext{
${ }^{1}$ Few drugs such as Viagra are not eligible for subsidies.
} 
identify effects of policies that increase the consumer payment (see for example Lexchin \& Grootendorst (2002) for a review), is that I have knowledge of purchase dates that allows me to investigate the phenomenon of stockpiling. This leads the researcher to overestimate price effects, but it also points to inefficiencies in the reimbursement scheme, i.e., people buy more or time their purchases because of the insurance. This information turns out to be crucial in my analysis and has important implications for other papers that use changes in cost sharing over time for identification within this area.

One of the important shortcomings of the existing literature is the lack of information about differential effects of co-payment across types of drugs. I contribute to the literature by analyzing two commonly used drugs that represent polar cases in several respects: insulin, which is used to treat a chronic and life-threatening condition afflicting mainly the elderly population and penicillin that is used to treat non-chronic, transitory conditions that are likely to affect the general population. Furthermore, because the entire Danish population was influenced by the policy change, my results are not limited to hold for a specific subgroup of the population with certain observable characteristics.

I find that the increased out-of-pocket payment for prescription drugs has a negative effect on utilization for both drugs under consideration. The increase in co-payment reduces utilization on the intensive as well as extensive margin for insulin. However, these effects are overestimated due to stockpiling of the medication, and I show that relying on changes in co-payment for identifying price responses, as is often done in the literature, can be misleading when one does not account for the heterogeneity of drugs. Although I do not present a formal model of stockpiling, my analysis clearly demonstrates that people plan their future consumption, and that this is more pronounced for the upper part of the income distribution. Further, the price elasticity of the propensity to purchase penicillin is estimated to be in the -.18 - -.35 interval, with the lower part of the income distribution being more price responsive. My results are confirmed by a wide range of sensitivity checks that include the incorporation of fixed effects and falsification tests.

The remainder of the paper is organized as follows. Section 2 provides a review of the existing literature. Section 3 outlines the institutional framework of the Danish market for prescription 
drugs. Section 4 describes the data and descriptive statistics. Section 5 describes the empirical strategy and identification. Section 6 presents the results, and section 7 concludes.

\section{Literature}

There is a substantial literature on utilization effects of changes in consumer co-payments. Most notably is probably the RAND Health Insurance Experiment (HIE) which ran from the late 1970's to the start of the 1980's. In a randomized experiment, non-elderly Americans were randomized into different insurance categories with varying co-payment levels, see Manning et al. (1987) and Newhouse (1993). The study did not focus on prescription drugs, but reported the price elasticity of overall health care demand to be around -.2.

Lexchin \& Grootendorst (2002) provide a review of the literature on consumer co-payment effects on prescription drugs utilization for the elderly. Based on the reviewed papers, they report price elasticities in the range -.34 to -.50 for the poor and chronically ill. However, most of the existing studies have shortcomings. First, as mentioned, they focus on specific subgroups of the population, for example the elderly or people with low health status in Medicare and Medicaid or individuals within a specific private health insurance plan. These subgroups are of course of great interest in themselves as they might be expected to be price responsive, but any results derived from specific subgroups are hardly representative of the general population. How the general population reacts to co-payment changes will be relevant input in policy designs and discussions in countries with government run health insurance that covers the entire population. Second, the outcome measures available are typically limited to the number of prescriptions filed or total expenses during a given month. This leaves out the possibility of analyzing differences in demand response to co-payment changes for different drugs. Tamblyn et al (2001) analyze the effect of increased co-payments on essential and less essential medications for the elderly and adults on welfare in Quebec, Canada. Using an interrupted time series regression design, they find that increased co-payments have a greater negative effect on utilization of less essential drugs compared to essential drugs.

Chandra et al. (2010) study price responsiveness for people enrolled in California Public Employees' Retirement System (CalPERS) with focus on the elderly population. In 2001 copayments went up for the fraction of enrollees under Preferred Provider Organizations (PPO), and in 2002 co-payments were increased for the fraction that received care through HMO's. With 
difference-in-difference techniques, the authors estimate drug utilization elasticities with respect to patient co-payments. The resulting elasticities are comparable to the RAND HIE estimates.

In another paper, Contoyannis et al. (2005) estimate the price elasticity for prescription drugs in the presence of a nonlinear price schedule for the elderly population (age 65 and over) enrolled in the Quebec Public Pharmacare program in Canada. They also exploit time variation in cost-sharing. Their overall finding is a price elasticity ranging from -0.12 to -0.16 .

\section{Institutional Framework}

Denmark has universal and tax financed health insurance run by the government. This includes paid hospital treatments and GP visits. Prescription drugs are also part of the public health insurance plan, though with substantial co-payments. Before March 1 2000, prescription drugs were divided into two categories, Type A and Type B drugs, both with first dollar coverage. Type A drugs carried a $50 \%$ co-payment, whereas Type B drugs had a $25 \%$ co-payment. Drugs would be subject to the $50 \%$ co-payment if 'the drug has a safe and valuable therapeutic effect, unless there is a risk of unwanted excessive use ${ }^{2}$. Besides these requirements, a drug would be subject to a co-payment of $25 \%$ if the drug was used to treat 'a well-defined, often life-threatening condition and if the drug could not be used for less appropriate medical indications ${ }^{\prime}$. Besides these two broad groups, some exceptions were made: Insulin (part of anti-diabetics) was exempt of any co-payments, i.e., the consumer did not pay for the drug. On the other hand, drugs aimed at treating less dangerous ailments such as Viagra did not receive any subsidy (along with birth control medications).

From March 1 2000, this reimbursement scheme was discontinued. The new subsidy scheme was enacted by law on December $18^{\text {th }} 1998$, so consumers would to some extend know about the changes, and hence had the opportunity to react by e.g. stockpiling. Under the new regime, copayments became a function of expenditures: consumers would have to pay the full cost of prescription drugs if the yearly expenditures were below DKK $500^{3}$, i.e., $100 \%$ co-payment. When reaching the DKK 500 limit, co-payments were reduced to 50\%. Reaching DKK 1200 would reduce co-payments to $25 \%$ and $15 \%$ at DKK 2800. The first time after March 12000 an individual would go to the pharmacy and buy a drug, the individual specific accounting year would start. After exactly one year, the individual account would be zeroed. By far the most, but not all prescription

\footnotetext{
${ }^{2}$ Own translation, see http://www.ism.dk/publikationer/medicintilskud/kap06.htm

${ }^{3}$ DKK 500 is approximately US $\$ 100$.
} 
drugs, are subject to this general subsidy scheme. Some prescription drugs only qualify for the subsidy if they are prescribed for a specific condition, this scheme is named conditional subsidy. Apart from general and conditional subsidies, an individual can receive one-product, increased, chronic's, terminal, and municipality specific subsidies. One-product subsidies concern a specific type of product (and all its substitutes) that is subject to neither a general nor a conditional subsidy. A general practitioner makes the application on behalf of the patient, and the Danish Medicines Agency is decisive. If the subsidy is granted, all purchases of the given product will be added to the above mentioned expenditures in the same manner as purchases of products with general or conditional subsidies. Typically, the subsidy will be granted for life but may in certain cases be disbursed for shorter periods (for example if the product is not to be consumed over an extended period). Post-patent drugs are subject to generic substitution. Therefore subsidies are only granted to the cheapest alternative within a substitution group (more on this later). A patient can choose to get e.g. the branded version of a drug, but then has to pay the price difference. On behalf of the patient the doctor can apply for increased subsidy to cover this gap if the patient is allergic to some components of the generic alternative. People suffering from chronic illness can be granted a subsidy by the Danish Medicines Agency if they have very high drug expenditures (around DKK 18,000 per year). In-patient prescription drugs are free of charge and provided by terminal subsidy to dying patients who wish to spend the remaining of their lives at home or at a hospice. The municipality specific subsidies are income tested and are granted on the municipality level. In the subsequent analysis, all these different type of subsidies are included when considering the consumer out-of-pocket expenses.

This structure can potentially alter the average co-payment for different drugs. For example, expensive drugs used to treat chronic conditions would, all other things equal, be associated with a lower co-payment on average after the reform, since high price combined with extensive use would increase consumer expenditures, and hence decrease co-payment. Similarly, drugs used to treat nonchronic conditions, e.g. penicillin, are expected to be associated with high co-payments on average, given a sufficiently low total consumption over the year. However, insulin would surely have a different and higher average price. 


\section{Private Insurance}

Private market prescription drug coverage insurance plans exist alongside public health insurance in Denmark. The only significant player in this market is "Danmark" . Out of a population of 5.5 million, "Danmark" insures around 2 million Danes. The company offers four types of policies; Group 1, 2, 5, and Basis. Group 1 and 2 insurance (about 400,000 individuals in total) covers all prescription drug expenditures related to products granted one of the government subsidies described above and 50\% of all costs related to products without any government subsidy. Group 5 insurance (1.3 million individuals) covers $50 \%$ of expenditures of products receiving any government subsidy and $25 \%$ of costs related to products without any subsidy. Basis insurance does not cover any costs of drug purchase, but individuals buying this type of insurance may - no matter their health status - opt into any of the other insurance policies at any point in time. In 2007, Group 1 insurance had a yearly cost of about DKK 2,400, Group 2 insurance had a yearly cost of about DKK 3,200, Group 5 insurance had a yearly cost of about DKK 1,000, and Basis had a yearly cost of about DKK 400. In 1999, the expenditures of "Danmark" on prescription drug reimbursement were DKK 486 million, corresponding to $6.75 \%$ of total prescription drug spending.

Eligibility to be insured by "Danmark" is conditional on the following requirements: No person requesting membership in "Danmark" will be admitted if they suffer from chronic or returning medical conditions or any 'physical weaknesses'. Neither will they be admitted if they have consumed prescription drugs/pharmaceuticals during the 12 months leading up to the request for membership or if they have received treatment at a physiotherapist, a chiropractor or the like. Furthermore, the request to be insured must be made before the age of 60, the person making the request has to be in perfect health at the moment of acceptance into the policy, and the individual is required to have residency in Denmark. The policies of "Danmark" did not change over the period studied. In the current data set it is not possible to verify if a person is insured through 'Danmark' This will have implications for identification which I will discuss later.

\section{Pharmacies and Physicians}

Prescription drugs are sold at government licensed pharmacies only. All information about purchases is registered in a database at the Danish Medicines Agency. Pharmaceutical companies are free to set prices, but they have to report these to the Danish Medicines Agency every 14 days.

\footnotetext{
${ }^{4}$ The insurance policies of "Danmark" provide coverage for a number of other medical treatments, e.g. dentistry.

${ }^{5} \mathrm{I}$ am working on adding this information.
} 
The Danish Medicines Agency then announces pharmacy retail prices which means that the consumer is met with the same price of a specific product no matter at which pharmacy the purchase is done. As mentioned above, Denmark has generic substitution. During the period under study in this paper, a consumer would only get reimbursed for the average price of the two cheapest substitutes within a substitution group. Substitutes are defined by having the same dose of the active substance as well as the same use (tablets, capsules etc) as the branded version. The pharmacy is required by law to sell the cheapest drug within a substitution group unless otherwise stated by the prescribing doctor or unless the consumer specifically requests something else. However the consumer would not get full reimbursement in the latter case. Drugs still under patent protection would receive subsidy for the full price. It is important to stress that the general practitioners do not have any direct financial incentives to prescribe certain types of medications.

Both prescription and non prescription drugs sold in Denmark carry a seven digit identifying code called ATC (Anatomical Therapeutic Chemical). It is a worldwide standard for classification of drugs that is run and maintained by the WHO. All drugs are classified in groups on five levels. For an example of an ATC-code, see Appendix A.

\section{Drugs Studied}

To shed light on the possible heterogeneity in reaction to co-payment changes over prescription drugs, I focus on two different drugs; penicillin which is an antibiotic and insulin (anti-diabetic). I focus on these drugs for two reasons: First of all, focusing only on a couple of drugs allows me to carry out a more rigorous and detailed analysis, compared to an alternative of evaluating the reform's impact on all drugs. Second, the antibiotic drug is used to treat acute and non-chronic conditions that may affect the general population. Penicillin is interesting as it is expected to face a huge increase in average co-payment after the reform. The typical penicillin consumer will use a small amount of prescription drugs (more on this later) and is therefore not likely to receive any subsidy immediately after the introduction of the reform. Insulin on the other hand is used to treat a chronic medical condition (diabetes) that requires daily intake of the drug, and patients in treatment will have a high degree of certainty regarding future consumption. These consumers are therefore expected to react differently to announced changes in prescription drug reimbursements. It is likely that any differences in reaction to the reimbursement changes over these two categories of drugs will carry over to other drugs with similar characteristics. 
Penicillin V (phenoxymethylpenicillin) - known as penicillin in layman terms - is one of the most frequently prescribed drugs in Denmark as measured in number of prescriptions; see Simonsen et al. (2010). It carries the ATC-code J01CE02. Suppliers of penicillin in the Danish market include Sandoz and Meda. Penicillin is used to treat a large number of bacterial infections, mainly in the upper and lower respiratory tract (e.g. tonsillitis, pneumonia) and certain skin infections. Before the reform the co-payment on penicillin was 50\%. The diseases for which penicillin treatment is required are also non-chronic which makes stocking-up less likely to take place. Chronic infections are treated with other antibiotic drugs.

Insulin is a group of anti-diabetic drugs. It is an anabolic hormone produced in the body to regulate the metabolism of carbohydrates. Patients diagnosed with Type 1 diabetes do not produce this hormone themselves. Insulin is also used to treat Type 2 diabetes in cases where relevant changes in lifestyle are not enough to control the disease (Type 2 diabetics have less insulin-sensitive tissue and therefore need a higher concentration of the hormone in the body). In relation to the ATC system, insulin is a group identified by the first four digits, ATC level 3, A10A. Insulin is then further broken down into groups on ATC level 4, according to how fast the insulin is processed in the tissue. Fast-acting insulin medicines include the ATC-codes A10AB01 ('Novo Nordisk', 'Eli Lilly' and 'Paranova Danmark'), A10AB04 ('Eli Lilly') and A10AB05 ('Novo Nordisk'). Intermediate-acting insulin is sold under the ATC-code A10AC01 ('Novo Nordisk', 'Eli Lilly' and 'Cross Cimilar A/S') during the period that I am studying. Finally, intermediate-acting insulin combined with fast-acting insulin is sold under the ATC-codes A10AD01 ('Novo Nordisk' and 'Eli Lilly') and A10AD04 ('Eli Lilly'). To sum up, 3 out of the 6 different ATC-codes for insulin have strictly more than one supplier, whereas the other 3 have only one supplier. Insulin has the distinct feature that it was completely free for the consumer prior to the reform (co-payment of $0 \%$ ). Diabetes being a chronic condition, the post-reform average co-payment percent of insulin is likely to be low, however it is likely to have an out-of-pocket price strictly greater than zero. As opposed to the case of penicillin, consumers will have some certainty regarding their future consumption, giving them strong incentives to stock-up on insulin before the reform change, which of course makes the use of changes in co-payment problematic for identifying price responses. I will address this problem by removing observations from the data set that are close to the reform date to shed light on the degree of stockpiling. 


\section{Data and Descriptive Statistics}

The original data set used consists of a $20 \%$ random sample of the Danish population obtained from the Danish Medicines Agency through Statistics Denmark. It contains recordings of all individual prescription drug purchases in the period 1995-2003. It includes quantities sold on each prescription, as measured by $\mathrm{DDD}^{6}$ (defined daily dose), active chemical ingredient (ATC code), brand name and form, total price, the associated reference price, the exact day of purchase as well as out-of-pocket price. All subsidies received from the government, i.e., the general subsidy, conditional subsidy etc. are accounted for in this out-of-pocket price. The payment received by the private insurance company "Danmark" however is not.

In table 1 I report descriptive statistics for weekly sales of insulin. I distinguish between two different periods, a year before March 12000 and a year after, to see how the change in reimbursement is associated with sales volumes, number of DDDs per prescription redeemed, number of people in treatment and prices. As can be seen from Table 1, the average number of DDDs sold per week is lower in the post-reform period with a decline from 78,836 to 58,894 . The average out-of-pocket price has increased dramatically, from basically zero ${ }^{7}$ (DKK 0.06) to DKK 2.92 in the post-reform period. The average total price is more or less unchanged (DKK 10.28 to DKK 10.62). The average number of filed prescriptions per week has fallen from 1,475 to 1,020. Furthermore, the average number of DDDs per filed prescription has fallen from 51.33 to 47.70 , and the number of individuals buying insulin has declined from at weekly average of 1,043 to 809 .

TABLE 1

INSULIN - DESCRIPTIVE STATISTICS - WEEKLY

\begin{tabular}{l|cccccccc}
\hline \multicolumn{4}{c}{} & \multicolumn{3}{c}{$01.03 .1999-29.02 .2000$} & & \multicolumn{3}{c}{$01.03 .2000-28.02 .2001$} \\
\hline & Mean & Std Dev & Min. & Max. & Mean & Std Dev & Min. & Max. \\
Total Volume (in DDD) & $78,836.42$ & $57,263.59$ & $38,362.50$ & $424,143.75$ & $48,894.83$ & $15,326.47$ & $13,687.50$ & $79,687.50$ \\
O-of-P per DDD (in DKK) & 0.06 & 0.03 & 0.01 & 0.13 & 2.92 & 1.46 & 1.42 & 7.02 \\
Avg. Price per DDD & 10.28 & 0.46 & 9.54 & 11.40 & 10.62 & 0.42 & 9.40 & 11.00 \\
\# Prescriptions & $1,475.60$ & 750.07 & 826.00 & $5,977.00$ & $1,020.58$ & 296.90 & 305.00 & $1,596.00$ \\
Avg. DDD per Prescription & 51.33 & 4.66 & 46.44 & 70.96 & 47.70 & 2.91 & 42.58 & 62.71 \\
Persons in Treatment & $1,043.46$ & 376.04 & 623.00 & $3,242.00$ & 809.06 & 222.87 & 235.00 & $1,238.00$ \\
\hline Not St
\end{tabular}

Note: Statistics Denmark, 20\% random sample. Descriptive statistics on insulin consumption. ATC4: A10AMean, standard deviation, min and max over weekly sales.

\footnotetext{
${ }^{6}$ See http://www.whocc.no/atcddd/atcsystem.html

${ }^{7}$ If you redeem a prescription at the pharmacies outside of normal business hours, a small fee is charged if the prescription is a refill (multiple pick-ups).
} 
From table 2 we see that penicillin is the most frequently prescribed of the two drugs and with most individuals receiving treatment. There is a slight increase in the number of DDDs per prescription from the first period to the next, however this is very small. The out-of-pocket payment per DDD has increased by a factor 1.5 .

TABLE 2

PENICILLIN - DESCRIPTIVE STATISTICS - WEEKLY

\begin{tabular}{l|cccccccc}
\hline \hline \multicolumn{4}{c}{} & \multicolumn{3}{c}{$01.03 .1999-29.02 .2000$} & \multicolumn{4}{c}{$01.03 .2000-28.02 .2001$} \\
\hline & Mean & Std Dev & Min. & Max. & Mean & Std Dev & Min. & Max. \\
Total Volume (in DDD) & $27,773.91$ & $4,987.82$ & $20,791.54$ & $38,775.72$ & $28,013.37$ & $4,371.97$ & $21,510.77$ & $39,880.01$ \\
O-of-P per DDD (in DKK) & 3.23 & 0.19 & 2.63 & 3.39 & 5.33 & 0.60 & 4.60 & 6.67 \\
Avg. Price per DDD & 6.72 & 0.44 & 5.46 & 7.07 & 7.06 & 0.11 & 6.95 & 7.34 \\
\# Prescriptions & $3,392.85$ & 588.83 & $2,541.00$ & $4,667.00$ & $3,375.67$ & 523.08 & $2,548.00$ & $4,752.00$ \\
Avg. DDD per Prescription & 8.18 & 0.08 & 8.00 & 8.39 & 8.30 & 0.07 & 8.08 & 8.48 \\
Persons in Treatment & $3,340.29$ & 586.15 & $2,492.00$ & $4,608.00$ & $3,324.90$ & 519.77 & $2,491.00$ & $4,680.00$ \\
\hline
\end{tabular}

Note: Statistics Denmark, $20 \%$ random sample. Descriptive statistics on penicillin consumption. ATC:J01CE02 Mean, standard deviation, min and max over weekly sales.

A feature the two drugs have in common is that the reform was associated with large changes in the average co-payment.

Table 3 contains descriptive statistics on consumption of the specific drug alone for penicillin and insulin. Mean and median total expenditures on insulin are DKK 4,600 and DKK 4,200 respectively, but with basically zero co-payment (O-O-P). That mean and median consumption measured by DDD amounts to more than 365 relates to the fact that there are different types of insulin, i.e., fast-acting etc. Regarding penicillin, the average consumer buys 10 DDDs, and pays half of the total out-of-pocket cost. This indicates that the out-of-pocket price of penicillin will increase with almost $100 \%$ just after the reform for many consumers.

TABLE 3

\begin{tabular}{|c|c|c|c|c|c|}
\hline & & Mean & $\overline{S t d}$ Dev & Median & \# Obs. \\
\hline \multirow{3}{*}{ sulin } & DDD & 435.48 & 267.75 & 393.75 & 7,485 \\
\hline & O-o-P & 25.89 & 54.57 & 0.00 & 7,485 \\
\hline & Tot. Exp. & $4,600.24$ & $2,897.54$ & $4,184.30$ & 7,485 \\
\hline \multirow[t]{3}{*}{ enicillin } & DDD & 10.67 & 7.64 & 8.00 & 134,092 \\
\hline & O-o-P & 32.76 & 22.47 & 26.20 & 134,092 \\
\hline & Tot. Exp. & 68.30 & 45.98 & 53.45 & 134,092 \\
\hline
\end{tabular}

Note: Statistics Denmark, 20\% random sample of people aged18 and above. 'O-o-P' and 'Tot. Exp.' are in DKK 
Table 4 provides descriptive statistics on the total consumption of prescription drugs by drug category for the calendar year 1999. It shows the yearly total consumption by someone who redeemed a penicillin prescription sometime during 1999 or someone who redeemed an insulin prescription during 1999 together with the general population. This is done to shed light on the difference in drug consumption over the two groups.

\section{TABLE 4}

TOTAL CONSUMPTION OF PRESCRIPTION DRUGS

BY CATEGORY - 1999

\begin{tabular}{ll|cccc}
\hline \hline \multicolumn{1}{|c}{ Insulin } & \multicolumn{1}{c}{ Mean } & Std Dev & Median & \# Obs. \\
\hline & DDD & $1,412.54$ & $1,405.61$ & 921.52 & 7,485 \\
& O-o-P & 945.60 & $1,519.04$ & 371.05 & 7,485 \\
& Tot. Exp. & $8,807.05$ & $8,322.57$ & $6,961.60$ & 7,485 \\
Penicillin & DDD & 376.04 & 749.00 & 57.00 & 134,092 \\
& O-o-P & 536.83 & $1,107.44$ & 150.70 & 134,092 \\
& Tot. Exp. & $2,043.90$ & $4,518.52$ & 391.88 & 134,092 \\
Gen. Pop. & DDD & 262.16 & 580.06 & 19.58 & 820,889 \\
& O-o-P & 373.08 & 894.16 & 59.60 & 820,889 \\
& Tot. Exp. & $1,407.83$ & $3,615.15$ & 155.25 & 820,889 \\
\hline Note: Statistics Denmark, 20\% random sample of people aged 18 and \\
above. 'O-o-P' and 'Tot. Exp.' are in DKK.
\end{tabular}

The first thing to notice is that very few people are being treated with insulin compared to penicillin. $16.3 \%$ of the Danish population aged 18 or above redeemed at least one penicillin prescription during the year 1999, whereas less that $1 \%(0.9 \%)$ bought insulin. Measured by total expenditures (Tot. Exp.), consumers who bought insulin are sicker in general. With mean and median levels of about DKK 9,000 and DKK 7,000 respectively, this is in stark contrast to the penicillin group with mean and median at DKK 2,000 and DKK 400. The corresponding figures for the general population are DKK 1,400 and DKK 155. Compared to the figures in table 3, this suggests that insulin amounts to roughly half of the total prescription drug expenditures for insulin consumers. The consumption level of people who buy penicillin is actually very similar to that of the population in general. Notice that the general population includes individuals who do not buy drugs. Furthermore, with total expenditures roughly at DKK 7,000, the median insulin consumer would expect to end her individual accounting year in the new reimbursement regime in the bracket that carries a $15 \%$ co-payment on additional purchases. In contrast to this, the median penicillin consumer with expenditures at DKK 400 will expect to face the full cost of his/her medications. This has important implications for identification as we will discuss later. 
For a graphical inspection I aggregate total sales by drug category on a weekly basis, as measured in DDD, a year before and after the drug reimbursement reform. I do not consider calendar weeks, but let the first week in the post-reform period start on March 1. Similarly, the average total price and average consumer co-payment is calculated (measured in DKK). I also calculate the average number of daily doses per prescription filed, as well as the number of prescriptions per drug per week and the number of persons being treated each week. The latter three, together with total sales volume will measure any change in utilization. Changes in total sales, together with the number of prescriptions redeemed, will tell how the market for a given drug reacts as a whole to the reform change. The average number of daily doses per prescription is a measure of consumption on the intensive margin, i.e., do individuals by more of the drug. The number of people receiving treatment measures changes on the extensive margin, i.e., does more people initiate treatment with the drug. The total price of the drug will be my measure of how prices react to the changes in co-payment. That is, do the firms change their prices as a reaction to changes in co-payments. Last but not least, the average consumer payment will be calculated.

The outcome variables are graphed below. In figure 1 the total volume per week as well as the average number of DDDs per filed prescription for insulin are plotted. As can be seen, there is a noticeable increase in the number of DDDs sold in the weeks just prior to the regime change and a decline just after. Also, the number of doses on each prescription increases sharply just before the regime change. Week 0 is March 1 2000, and week -1 is the week before etc.

The graphs for number of prescriptions and number of persons in treatment show similar patterns; see Appendix B. 
FIGURE 1

TOTAL DOSES AND AVERAGE DOSES PER PRESCRIPTION BY WEEK - INSULIN
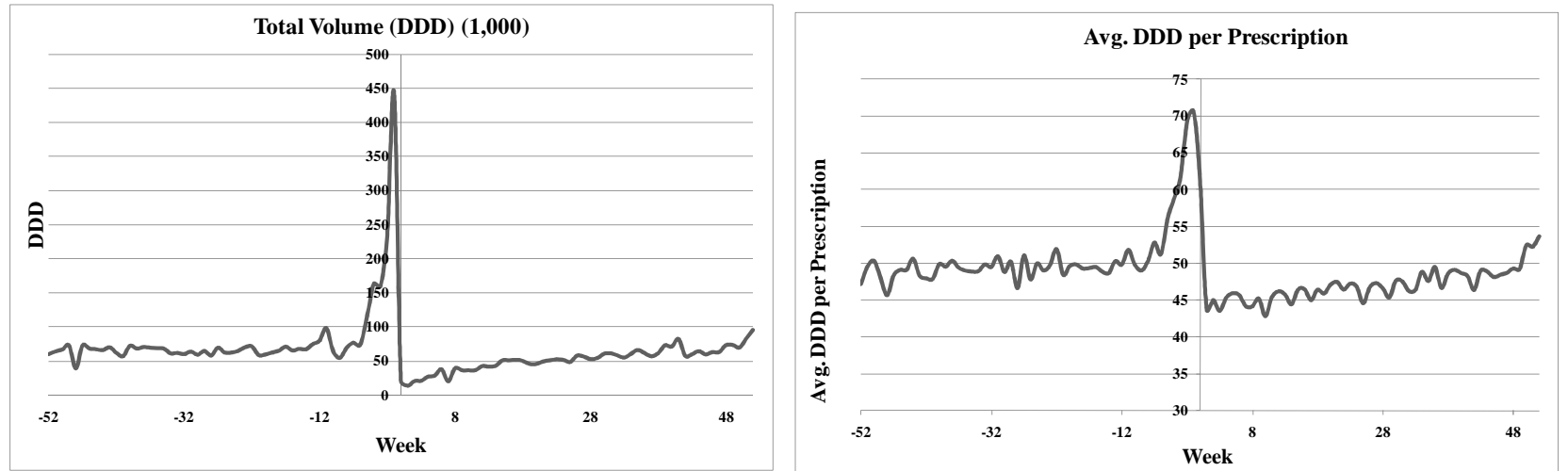

Note: Statistics Denmark. 20\% random sample. Number of DDD's sold per day (thousands) and average number of DDDs per prescription filed, insulin.

Figure 1 strongly suggests a forward looking element in the consumption of insulin. That is, individuals anticipate that insulin is going to be more expensive in the future, and therefore they stock up on it while they can get it for free. This fact makes it key to discard some of the observations close to day zero in the empirical section. Also note the upwards trend in the postreform period. As the insulin category consists of 5 different (traded) ATC-codes, it is relevant to check if the pattern in figure 1 is the same for all insulin drugs. The peak in sales just before the reform date is evident for all 5 drugs, but it is more pronounced for A10AB04 (fast-acting), A10AB01 (fast-acting) and A10AC01 (intermediate-acting); see Appendix B. From the market share graph in Appendix B it can also be seen that there is a slight change in the composition of the drugs. The intermediate-acting A10AC01 consists of 40-50\% of all the DDDs sold through the period. After the reform there is a slight fall in the relative share for this intermediate-acting drug. The fast-acting insulin A10AB01, with a market share around 30\% through the period, displays a similar pattern. The combined intermediate/fast-acting drug A10AD01 experiences an inverted pattern compared to the two other drugs; its share of the total is just below $20 \%$ the weeks before the reform and jumps up to around $30 \%$ after the reform date, and then decreases again. This would suggest that the stocking up on this particular drug is less intense. 
FIGURE 2

AVerage OUt-OF-Pocket Price PER DOSES AND AVERAge TOTAL PRICE PER DOSES - INSUliN
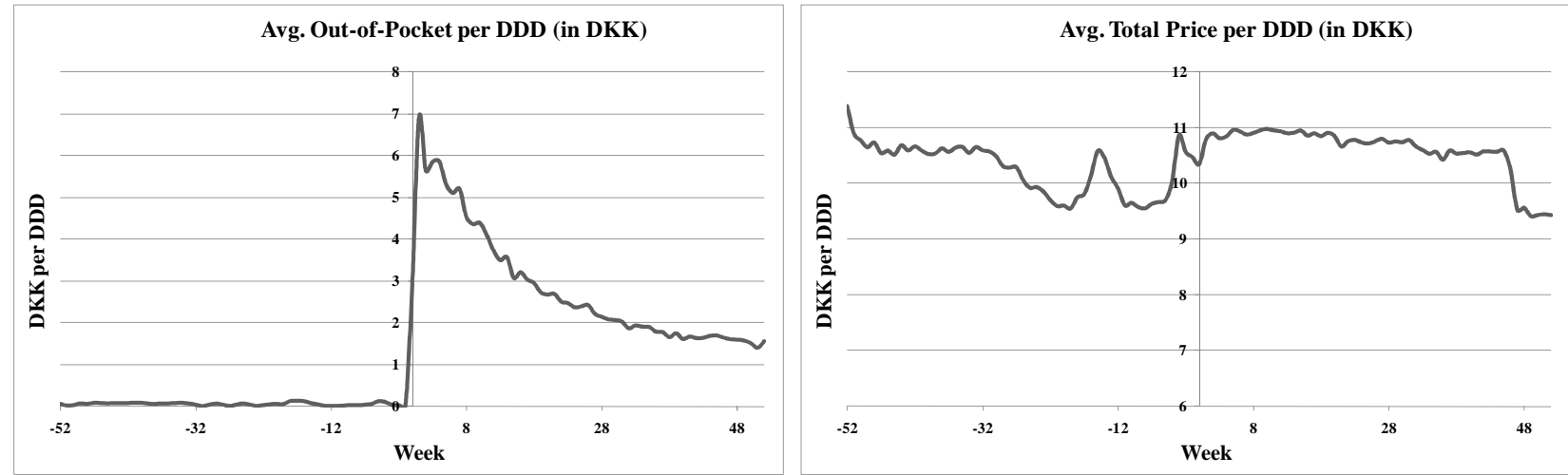

Note: Statistics Denmark. 20\% random sample. Average out-of-pocket payment per DDD and average total price per DDD, insulin.

Figure 2 pictures the average out-of-pocket price per DDD and the average total price of insulin. The out-of-pocket price is zero in the first year and increases dramatically at the start of the next period. However, the average price decline again and reaches a level around DKK 2 per DDD. The gradual declines in average out-of-pocket payment is caused by consumers reaching a high level in terms of drug expenditures which drives down their co-payment (see section 3). Regarding the total price, the first year the price is constant at around DKK 10.5, but with two plunges to DKK 9.5 around 20 and 10 weeks before the reform. After the reform it starts out just below DKK 11, however with at slightly decreasing trend. Around week 45 after the reform, it suddenly falls from DKK 10.5 to DKK 9.5. The price series for the individual ATC-codes are in Appendix B. The price plunges 10 and 20 weeks before the reform seems to be driven by the drugs A10AC01 and A10AD01 and to some extend A10AB01. Note that these three drugs all have strictly more than one producer. The price drop around week 45 in the post-reform period is similar for all 6 ATC-codes.

Figures 3 and 4 display the same series for penicillin. The most notable difference between the insulin sales and penicillin sales is the strong seasonal component in the latter. The penicillin sales peak in the winter months which we might have expected (it is used to treat e.g. pneumonia). The seasonality is also prevalent in the average number of doses per prescription. With respect to the price series in figure 4, we see the same jump in out-of-pocket price at the reform date. The average out-of-pocket price also declines over time for penicillin, however not as much as that of insulin did. A subset of the consumers who buy penicillin will be individuals with chronic conditions and therefore people with high drug expenditures. As we saw previously, a person in insulin treatment is likely to hit the part of the subsidy bracket where co-payment is only $15 \%$, which of course will 
drive down the average out-of-pocket price. The total price per doses is unaffected around the regime change.

\section{FIGURE 3}

Total Doses AND Average Doses PER PRESCRIPTION By WEEK - PENICILLIN
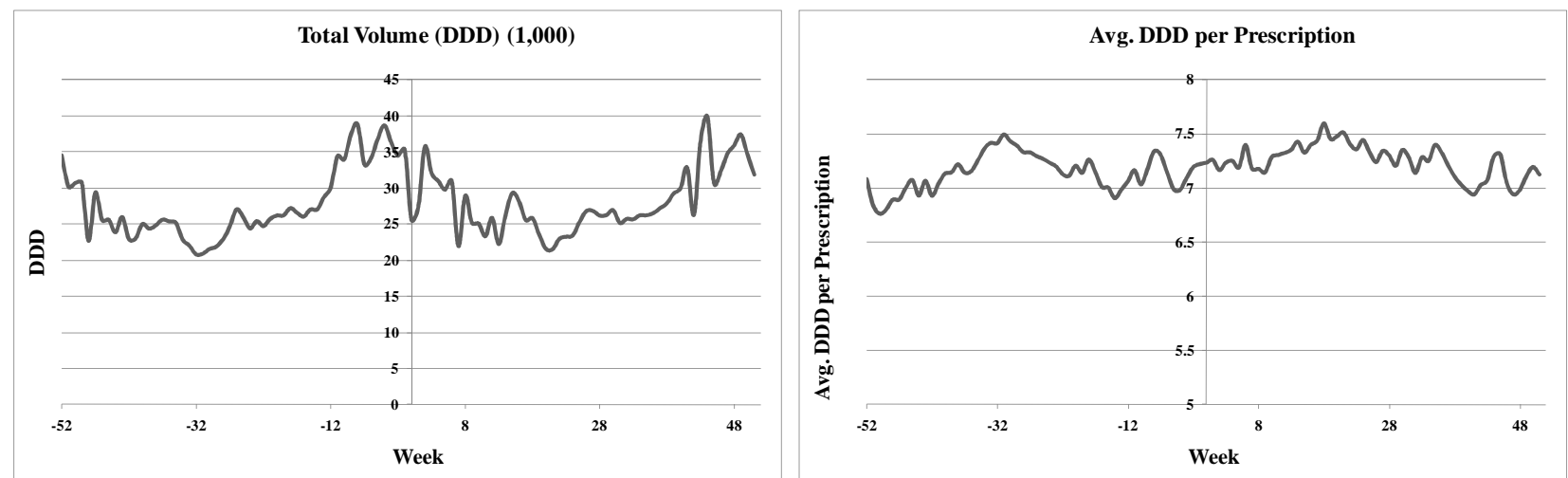

Note: Statistics Denmark. 20\% random sample. Number of DDD's sold per day (thousands) and average number of DDD's per prescription filed, penicillin.

FIGURE 4

Average Out-OF-Pocket Price Per Doses AND AVERAge Total PRICE PER Doses -

PENICILLIN
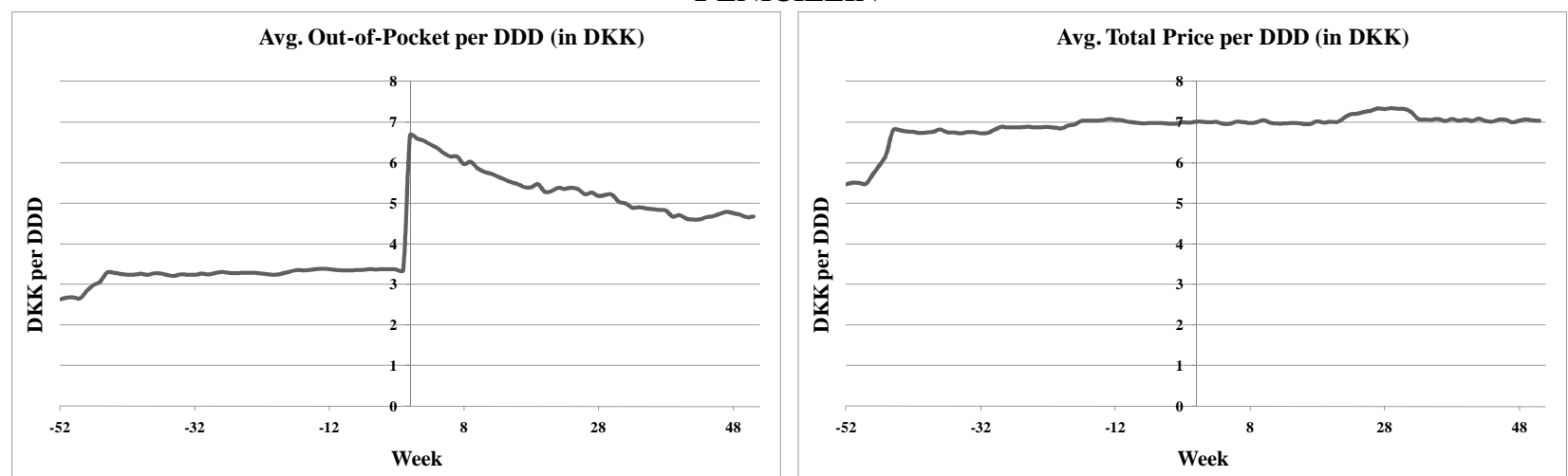

Note: Statistics Denmark. 20\% random sample. Average out-of-pocket payment per DDD and average total price per DDD, penicillin.

I now turn to the empirical strategy of the paper, followed by a description of the identification strategy. 


\section{Empirical Strategy}

The empirical part of the paper is divided into two different sections. This is done in order to address the inherent characteristics of the products studied. As figure 1 suggests, insulin is stockpiled prior to the reform date. Although I do not estimate a model that explicitly handles this phenomenon, I will discard observations close to the reform date to evaluate whether the reform results in any long term effects. Penicillin sales on the other hand, as seen in figure 3, have a very strong seasonal component to it. In contrast to insulin, stockpiling penicillin did not seem to be an issue. So to circumvent the seasonal component of the sales, we can use observations arbitrarily close to the reform data to estimate an effect of the price change.

\subsection{Penicillin}

Figure 3 clearly demonstrated a strong seasonal component of the penicillin consumption. An empirical specification that uses data a year before and after the reform might not fully capture this variation. Further, comparing consumption over two years can be problematic, especially for penicillin if, say, the winter months in one of the years were colder, and hence implied a greater outbreak of certain infections. Then this would ultimately confound the results. If we only consider purchases very close to the reform change, i.e., days immediately before and after it, we can avoid such unmeasured variation confounding the analysis. This is basically a regression discontinuity design in time; see Imbens \& Lemieux (2008) and Hahn, Todd, \& van der Klaauw (2001). The proposed outcome of interest is the propensity that an individual goes to the pharmacy and redeems a penicillin prescription on a given day close to the reform. As we saw in section 4, the number of consumers who bought penicillin and the number of prescriptions were almost identical, and the reform did not seem to have any impact on the amount of doses supplied per prescription. Of those who buy penicillin more than $90 \%$ only redeem one prescription during a year. We would not expect effects on the intensive margin, at least not to the same degree as the case for insulin. Hence, the outcome of interest should be whether or not an individual engages in treatment. I propose to estimate the propensity to purchase with the following probit model:

$$
P(\text { purchase }=1 \mid I, T, D)=\Phi\left(\beta_{0}+\beta_{1} I_{i t}[t \geq 0]+\beta_{2} T_{t}+\beta_{3} D_{i t}\right)
$$

where $I$ is a reform indicator, $T$ is a time trend that captures the seasonal curvature and $D$ are dummies to capture any weekday specific variation. The parameter of interest is $\beta_{1}$. The 
introduction of the new subsidy scheme implies, on average, a huge increase in consumer copayment. If we are willing to make the plausible assumption that no other factors determining the propensity to purchase 'jumps' at the reform date, we have identified a causal relationship between consumer co-payment and the propensity to purchase.

\subsection{Insulin}

In the estimation part of the paper, the outcome variables for insulin are basically the same as in the graphical analysis. I propose to estimate the following fixed effect model for each outcome of interest:

with

$$
\begin{aligned}
& y_{i t}=\alpha_{i}+\beta_{1} I_{i t}[t \geq 0]+\beta_{2} \operatorname{TREND}_{t}+\beta_{3} I_{i t}[t \geq 0] X \text { TREND } \\
& t
\end{aligned}
$$

and $i$ indexing the individual and $t$ indexing time. I distinguish between 8 periods of exactly 90 days each, with four of the periods before the reform date and four after. $\alpha_{i}$ is the individual level fixed effect that captures time-invariant factors affecting the outcomes. Note that I do not include controls for any individual level characteristics. Since the time-span is only two years, most of the socioeconomic characteristics, including income, will be constant and hence captured by the fixed effect. The time periods are changed from weeks to 90 days. As we saw in table 1, the average insulin prescription contained 40-50 daily doses, so maintaining the weekly time dimension would leave us with many observations without purchase. Further, there did not seem to be seasonal variation in the insulin consumption, so a model allowing us to control for trends in utilization seems sufficient. Furthermore, the trend is interacted with the reform dummy. The parameter $\beta_{3}$ will capture changes in the trend. A steeper trend prior to the reform $\left(\beta_{3}\right.$ is negative) is suggestive evidence of stockpiling.

I focus on six outcome measures closely related to the outcomes of the graphical analysis. $O O P / D D D$ is the (individual level) average co-payment per defined daily doses in a given period, $D D D$ is the total quantity of the drug bought in the period, $T P / D D D$ is the average total price per defined daily doses, PRES is the number of prescriptions the person redeemed, DDD/PRES is the average number of defined daily doses per prescription the person redeemed, and $O O P / T P$ is the 
ratio between co-payment and total price. The interpretation of these is similar to the outcomes in section 4, only on the individual level. For the price variables I estimate two different specifications of the above model; one with and one without the time trend. A trend will capture the decline in price caused by the nature of the new subsidy scheme and hence, the effect of the reform on prices will be overestimated.

For consumers who buy insulin in the year before the reform, I estimate the effect of the reform on their consumption of other drugs to see if there are any spillover effects. In this case, I consider two extra variables, ESSENTIAL and LESS ESSENTIAL. The former measures the number of essential drugs bought and the latter is the complement set (termed less essential for convenience). The essential drugs are defined according to Tamblyn et al. (2001): "medications that prevent deterioration in health or prolong life and would not likely be prescribed in the absence of a definitive diagnosis".

Even though the length of each time period is 90 days, a complication of the model is that the quantity variables will be censored at zero (roughly 20\%). To address this problem I use the estimator proposed by Honoré (1992) that allows for individual fixed effects in a censored regression model. The estimator is semi-parametric in the sense that it does not put any parametric assumptions on the distribution of the fixed effect. The key identifying assumption is the conditional pairwise exchangeability of the transitory error term, $u_{i t}$, i.e., that $\left(u_{i t}, u_{i s}\right)$ is distributed like $\left(u_{i s}, u_{i t}\right)$ conditional on the regressors. This assumption can then be used to construct moment conditions that do not depend on the individual fixed effects. This estimator is used for the quantity variables, and the standard linear within groups estimator is used for the price variables ${ }^{8}$. The standard linear within groups estimator is also used for the censored variables as a sensitivity check.

\subsection{Identification issues}

The key identifying assumption is that the introduction of the new reimbursement scheme in March 2000 caused exogenous variation over the average out-of-pocket payment for prescription drugs and that it is through this change in consumer co-payment we see changes in utilization etc.

\footnotetext{
${ }^{8}$ Prices are set to missing in periods with no purchases and are therefore not included in the estimation. An alternative approach is to recode missing values as zeroes and adding a dummy variable to the explanatory variables that takes the value one in this case and zero otherwise.
} 
Using a reform like the one presented in this paper raises some important identification issues that need to be addressed. First of all, a major change in reimbursement rules does not happen over night without people knowing it. The reform was signed into law by the Danish Parliament in 1998, so consumers knew before-hand that there would be changes. Since prescription drugs are a type of good that need not to be consumed immediately when it is purchased, intertemporal substitution between time periods is possible. That is, if consumers foresee big price increases, they may stockup on the medications they consume, which was the case with insulin. This fact leads us to overestimate the effect of the increase in price that the reform causes, thus no price responsiveness derived will be valid. A somewhat similar problem is present in the marketing literature when estimating price elasticities of demand for storable goods using price reductions under sales as price variation; see Hendel \& Nevo (2006) and Hendel \& Nevo (2009). This is the reason it is important to discard observations close to the reform date, at least for insulin. The nature of the new subsidy scheme also introduces a new problem that makes it difficult to report any meaningful direct link between prices and quantities. Insulin consumers have very high annual prescription drug expenditures, and roughly half of these expenditures stem directly from insulin. When the average insulin consumer goes to the pharmacy, under the new subsidy scheme, he or she knows that their current purchase of insulin will lower the future price on other drugs (and insulin as well). So if the forward looking consumer incorporates price reductions for future consumption, the real marginal price is lower than the marginal price we observe. Keeler, Newhouse \& C. E. Phelps (1977) dubs this price the effective price. This does not suggest that it is pointless to investigate how insulin utilization changes as a consequence of the reform, only that we should not over interpret any y percentage decrease in utilization associated with an x percent co-payment increase.

Penicillin is another matter since it is used to treat non-chronic conditions. The future consumption of non-chronic drugs can be very hard to predict, so we do not expect consumers to stock up on them, which seems to be backed up by the data. Another feature which suggests that penicillin is the type of drug you 'buy when you need it' is the strong seasonal component of the aggregate consumption we saw earlier. Almost $90 \%$ of the people who consumed penicillin in 1999 redeemed only one prescription (of penicillin). Also, the median person who received treatment with penicillin in 1999 had a total expenditure level just below DKK 400, for all prescription drugs. This tells us that the median penicillin consumer does not expect to consume enough for the subsidy to kick in under the new scheme if expectations are based on consumption in previous period. If the 
median penicillin consumer redeems a prescription immediately after the reform, the marginal price that we observe in the data will probably also be close to the true marginal price for the individual at least compared to the median insulin consumer. On that account, it is more meaningful to establish a direct link between co-payment increases and utilization changes especially when we consider the days very close to the reform date. Here everyone will be met with the same out-ofpocket price at the pharmacies (since all are in the beginning of their new subsidy year). Of course, a subset of those who buy penicillin immediately after the reform will be chronics in terms of other drugs, whose price response probably will be lower by means of the effective price. Bearing in mind that we do not attempt to estimate any structural parameters anyhow, the results from the analysis will still be relevant for public policy, i.e., it tells us what effect a $10 \%$ increase in consumer copayment will have on utilization within the present regime. As mentioned earlier, I am not able to observe membership of the private insurance company "Danmark". A subset of the consumers will have some of their co-payment covered by this company which will lead us to underestimate the price response. Hence, the effects should be seen as net of private insurance.

\subsubsection{Sample Selection}

For the insulin estimation, I put some restrictions on the sample. First of all, I discard all individuals who die within the two years considered (425 individuals out of 7652). Obviously, if a person dies a week into the new reform period, her consumption is lower in the second period but this is not due to the reform. I only consider individuals who make a purchase before the reform. In the estimation of effects on the consumption of other drugs for people who buy insulin, the sample also only consists of individuals who bought insulin in the pre-policy period. By doing this, I capture the effect on those staying in treatment with insulin, but also that of those who decide to drop out of insulin treatment.

Throughout the analysis for penicillin, only individuals aged 18 or above are considered. The primary reason for this choice is the different subsidy scheme which exists for individuals under 18.

I now turn to the estimation results. 


\section{Results}

\section{1 Results - individual level analysis}

\section{Insulin}

I now present the results from the individual level analysis outlined in section 5. In table 6, the results for insulin are reported. There is a large increase in the co-payment per DDD, and utilization has fallen both in terms of defined daily dosage and number of prescriptions. The number of DDDs per redeemed prescriptions has gone down as well. The total price per DDD has increased slightly, and the magnitude of the effect is very sensitive to inclusion of the time trend. When we discard the purchases done 90 days before and after the reform date, we still see a big effect on co-payment. The magnitude of the effect on utilization is roughly halved. This is most likely due to the stockingup effect. A similar reduction in utilization response is found in Chandra et al. (2010) when they remove observations close to the reform date, but they do not discuss stockpiling in great detail. However, even for the sub-sample the reform indicator suggests large reductions in doses purchased. Overall, the results of the individual level analysis are in line with the graphical inspection. As mentioned, the specifications with quantity outcomes are censored at zero and are therefore estimated using the semi-parametric estimator of Honoré (1992). As a sensitivity check these specifications were also estimated using the standard linear fixed effects model, and this did not change the conclusions (the numerical size of the point estimates differed somewhat).

The analysis is split down by high and low income (defined as being below/above the median income of the sample). The tables are placed in appendix D. The coefficient to the reform indicator is about $25 \%$ higher for the high income group than the low income group (the average number of doses purchased before the reform is lowest for the high income people). This suggests that stockpiling is more pronounced for people with high incomes or that they react more to the price change. As can be seen, the high income group also experiences a larger increase in the average copayment. That is, they stockpile because they expect larger price increases than people with low incomes. Another reason might simply be that people with high incomes are more able to plan their consumption. Note that liquidity constraints for the low income group cannot be an explanation as the drug was free. A graph similar to that of figure 1 broken down on income shows that the high income group intensifies their purchases relatively more than the low income group the last 10 weeks before the reform date (not reported). 
TABLE 6

FIXED EFFECT ESTIMATION - INSULIN

\begin{tabular}{|c|c|c|c|c|c|c|c|c|c|}
\hline & $O O P / D D D$ & & $T P / D D D$ & & OOP/TP & & $D D D$ & PRES & DDD/PRES \\
\hline & \multicolumn{9}{|c|}{ Full sample } \\
\hline \multirow[t]{2}{*}{$I[t \geq 0]$} & 3.17 & 10.67 & 0.3 & 1.45 & 0.3 & 0.95 & -443.87 & -7.92 & -3.45 \\
\hline & $(0.016)$ & $(0.05)$ & $(0.007)$ & $(0.026)$ & $(0.001)$ & $(0.005)$ & (12.999) & $(0.239)$ & $(0.751)$ \\
\hline \multirow[t]{2}{*}{ TREND } & - & -0.01 & - & -0.21 & - & 0.00 & 73.86 & 0.75 & 3.02 \\
\hline & - & $(0.007)$ & - & $(0.004)$ & - & $(0.001)$ & $(2.561)$ & $(0.039)$ & $(0.105)$ \\
\hline \multirow[t]{2}{*}{$I[t \geq 0] X$ TREND } & - & -1.30 & - & -0.05 & - & -0.11 & -7.75 & 0.37 & -2.13 \\
\hline & - & $(0.011)$ & - & $(0.006)$ & - & $(0.001)$ & (3.072) & $(0.052)$ & $(0.163)$ \\
\hline \# Obs. & 45,265 & 45,265 & 45,265 & 45,265 & 45,265 & 45,265 & 57,816 & 57,816 & 45,265 \\
\hline \multirow[t]{2}{*}{ Mean } & 0.06 & 0.06 & 10.33 & 10.33 & 0.01 & 0.01 & 369.85 & 7.02 & 55.50 \\
\hline & & ample - & cluding $\mathrm{c}$ & period & each sid & of refor & date & & \\
\hline \multirow[t]{2}{*}{$I[t \geq 0]$} & 2.59 & 8.20 & 0.18 & 1.90 & 0.24 & 0.725 & -197.44 & -2.58 & -8.40 \\
\hline & (0.014) & (0.066) & (0.008) & (0.037) & $(0.001)$ & $(0.006)$ & (15.636) & (0.308) & (1.014) \\
\hline \multirow[t]{2}{*}{ TREND } & - & 0.00 & - & -0.36 & - & 0.000 & 3.81 & 0.04 & 0.47 \\
\hline & - & $(0.01)$ & - & (0.006) & - & $(0.001)$ & (2.671) & (0.052) & (0.153) \\
\hline \multirow[t]{2}{*}{$I[t \geq 0] X T R E N D$} & - & -0.92 & - & 0.02 & - & -0.080 & 17.23 & 0.18 & 0.85 \\
\hline & - & (0.014) & - & $(0.008)$ & - & $(0.001)$ & (3.659) & $(0.072)$ & $(0.223)$ \\
\hline \#Obs. & 34,791 & 34,791 & 34,791 & 34,791 & 34,791 & 34,791 & 43,362 & 43,362 & 34,791 \\
\hline Mean & 0.06 & 0.06 & 10.40 & 10.40 & 0.01 & 0.01 & 320.46 & 6.47 & 52.83 \\
\hline
\end{tabular}

Note: Statistics Denmark, $20 \%$ random sample. Bold indicates significance at 5\% level. S.E. in (), clustered on person ID, 'Mean' is the sample average of outcome in the pre-policy period.

To make sure that the results are not driven by a peculiar calendar effect, I provide a graphical falsification test for insulin in which I consider an artificial reform date, namely March $1^{\text {st }} 1999$; see figure 5. There does not seem to be any changes in quantities nor out-of-pocket prices around March $1^{\text {st }} 1999$.

FIGURE 5

FALSIFICATION TEST - AVERAGE OUT-OF-POCKET PER DDD AND TOTAL DOSES BY WEEK INSULIN
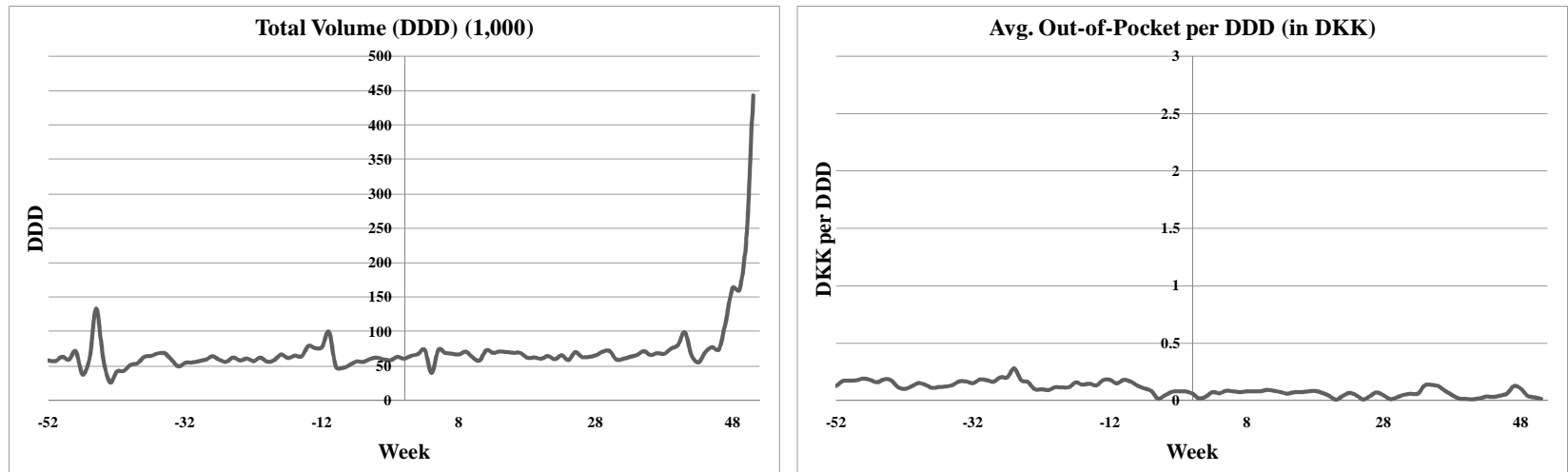

Note: Statistics Denmark. 20\% random sample. Number of DDD's sold per day (thousands) and average number of DDD's per prescription filed, insulin. 
As a last set of results on insulin, I report the utilization and price changes of other prescription drugs for individuals being treated with insulin; see table 7. All utilization measures decrease as a consequence of the reform; the results suggest a drop of -.7 in the number of essential drugs used and a drop of -1.04 for less essential drugs. There is a significant, positive time trend in utilization. We also see that the out-of-pocket payment for the other drugs has gone up. The total price per daily doses has gone down, but this result is sensitive to the inclusion of the trend, i.e., the effect is probably driven by the trend.

Considering the sub-sample where 90 days of each side of the reform is dropped, the results change somewhat. The effect on the average out-of-pocket payment per DDD is small and statistically insignificant in the specification without a trend. I still see fewer prescriptions redeemed and negative effects on the number of essential and less essential medications bought, however the coefficient estimates are halved compared to the full sample. Notice there is no significant change in the trend over the pre-post reform period which we would have expected if people stockpiled. However, it is not obvious that stockpiling of other drugs prior to the reform date is optimal. Remember that all other drugs than insulin carried a 25 or $50 \%$ co-payment. Hence, it is possible that the price of these drugs would be lower after the reform if expenditure levels were sufficiently high.

TABLE 7

FIXED EFFECT ESTIMATION - INSULIN - CONSUMPTION OF OTHER DRUGS

\begin{tabular}{|c|c|c|c|c|c|c|c|c|c|c|c|}
\hline & $O O P / D D D$ & & $T P / D D D$ & & $O O P / T P$ & & $D D D$ & PRES & DDD/PRES & ESSENTIAL & LESS ESS. \\
\hline & \multicolumn{11}{|c|}{ Full sample } \\
\hline$I[t \geq 0]$ & $\begin{array}{c}\mathbf{0 . 6 7} \\
(0.093)\end{array}$ & $\begin{array}{c}\mathbf{6 . 2 7} \\
(0.348)\end{array}$ & $\begin{array}{c}\mathbf{- 0 . 5 5} \\
(0.255)\end{array}$ & $\begin{array}{c}1.12 \\
(0.971)\end{array}$ & $\begin{array}{c}\mathbf{0 . 0 6} \\
(0.002)\end{array}$ & $\begin{array}{c}\mathbf{0 . 7 7} \\
(0.007)\end{array}$ & $\begin{array}{c}\mathbf{- 3 3 1 . 5 9} \\
(13.49)\end{array}$ & $\begin{array}{c}-\mathbf{4 . 4 0} \\
(0.169)\end{array}$ & $\begin{array}{c}\mathbf{- 7 . 0 0} \\
(1.165)\end{array}$ & $\begin{array}{c}\mathbf{- 0 . 7 2} \\
(0.040)\end{array}$ & $\begin{array}{c}\mathbf{- 1 . 0 4} \\
(0.055)\end{array}$ \\
\hline TREND & - & $\begin{array}{c}\mathbf{- 0 . 1 5} \\
(0.057)\end{array}$ & - & $\begin{array}{c}\mathbf{- 0 . 4 9} \\
(0.160)\end{array}$ & $\begin{array}{l}- \\
-\end{array}$ & $\begin{array}{l}\mathbf{- 0 . 0 1} \\
(0.001)\end{array}$ & $\begin{array}{l}\mathbf{7 6 . 5 9} \\
(2.727)\end{array}$ & $\begin{array}{c}\mathbf{1 . 0 2} \\
(0.037)\end{array}$ & $\begin{array}{c}\mathbf{1 . 1 8} \\
(0.192)\end{array}$ & $\begin{array}{c}\mathbf{0 . 1 0} \\
(0.006)\end{array}$ & $\begin{array}{c}\mathbf{0 . 1 0} \\
(0.009)\end{array}$ \\
\hline$I[t \geq 0] X$ TREND & - & $\begin{array}{c}\mathbf{- 0 . 9 0} \\
(0.082)\end{array}$ & - & $\begin{array}{c}0.06 \\
(0.229)\end{array}$ & - & $\begin{array}{c}\mathbf{- 0 . 1 2} \\
(0.002)\end{array}$ & $\begin{array}{c}-0.40 \\
(3.191)\end{array}$ & $\begin{array}{c}-0.07 \\
(0.045)\end{array}$ & $\begin{array}{c}\mathbf{0 . 8 1} \\
(0.274)\end{array}$ & $\begin{array}{c}\mathbf{0 . 0 8} \\
(0.009)\end{array}$ & $\begin{array}{c}\mathbf{0 . 0 9} \\
(0.013)\end{array}$ \\
\hline \# Obs. & 42,578 & 42,578 & 42,578 & 42,578 & 43,236 & 43,236 & 57,816 & 57,816 & 43,236 & 57,816 & 57,816 \\
\hline Mean & 2.50 & 2.50 & 8.31 & 8.31 & 0.34 & 0.34 & 312.96 & 5.74 & 55.99 & 0.89 & 2.15 \\
\hline \multicolumn{12}{|c|}{ Sub-sample - excluding one period on each side of reform date } \\
\hline$I[t \geq 0]$ & $\begin{array}{c}-0.12 \\
(0.101)\end{array}$ & $\begin{array}{c}\mathbf{3 . 5 0} \\
(0.523)\end{array}$ & $\begin{array}{c}\mathbf{- 0 . 9 7} \\
(0.234)\end{array}$ & $\begin{array}{c}0.73 \\
(1.239)\end{array}$ & $\begin{array}{c}\mathbf{- 0 . 0 2} \\
(0.002)\end{array}$ & $\begin{array}{c}\mathbf{0 . 4 3} \\
(0.010)\end{array}$ & $\begin{array}{c}\mathbf{- 2 9 4 . 7 6} \\
(20.66)\end{array}$ & $\begin{array}{c}-\mathbf{4 . 0 0} \\
(0.264)\end{array}$ & $\begin{array}{c}-3.07 \\
(1.928)\end{array}$ & $\begin{array}{c}\mathbf{- 0 . 2 9} \\
(0.055)\end{array}$ & $\begin{array}{c}\mathbf{- 0 . 6 5} \\
(0.086)\end{array}$ \\
\hline TREND & $\begin{array}{l}- \\
-\end{array}$ & $\begin{array}{c}-0.04 \\
(0.085)\end{array}$ & $\begin{array}{l}- \\
-\end{array}$ & $\begin{array}{c}0.12 \\
(0.201)\end{array}$ & $\begin{array}{l}- \\
-\end{array}$ & $\begin{array}{c}0.00 \\
(0.002)\end{array}$ & $\begin{array}{c}\mathbf{7 . 1 4} \\
(2.359)\end{array}$ & $\begin{array}{c}\mathbf{0 . 1 2} \\
(0.034)\end{array}$ & $\begin{array}{l}-0.15 \\
(0.311)\end{array}$ & $\begin{array}{c}\mathbf{0 . 0 5} \\
(0.009)\end{array}$ & $\begin{array}{c}\mathbf{0 . 0 3} \\
(0.014)\end{array}$ \\
\hline$I[t \geq 0] X T R E N D$ & - & $\begin{array}{c}-0.57 \\
(0.119)\end{array}$ & - & $\begin{array}{c}-0.38 \\
(0.283)\end{array}$ & - & $\begin{array}{l}\mathbf{- 0 . 0 7} \\
(0.002)\end{array}$ & $\begin{array}{l}\mathbf{5 5 . 1 6} \\
(4.381)\end{array}$ & $\begin{array}{c}\mathbf{0 . 6 6} \\
(0.057)\end{array}$ & $\begin{array}{c}\mathbf{1 . 3 9} \\
(0.440)\end{array}$ & $\begin{array}{c}\mathbf{0 . 0 6} \\
(0.012)\end{array}$ & $\begin{array}{c}\mathbf{0 . 0 9} \\
(0.020)\end{array}$ \\
\hline \# Obs. & 32,069 & 32,069 & 32,069 & 32,069 & 32,562 & 32,562 & 43,362 & 43,362 & 32,562 & 43,362 & 43,362 \\
\hline Mean & 3.64 & 3.64 & 10.94 & 10.94 & 0.40 & 0.40 & 196.47 & 3.56 & 55.56 & 0.60 & 1.42 \\
\hline
\end{tabular}

Note: Statistics Denmark, 20\% random sample. Bold indicates significance at 5\% level. S.E. in (), clustered on person ID, 'Mean' is the sample average of outcome in the pre-policy period. 
The analysis of other prescription drugs is also split down by income group; see appendix D. Again, the coefficient to the reform indicator is larger for the high income group when we consider the total amount of doses even though they buy fewer doses on average before the reform. This is true for the full sample as well as for the sub-sample. The results further suggest that the low income group drops out of relatively more essential as well as less essential treatments after the reform. This effect is muted when we consider the sub sample results though.

\section{Penicillin}

The first set of results for the individual level analysis for penicillin will consist of a graphical representation of the probability of purchase on the days in the neighborhood around the reform. Before we turn to that, we investigate the underlying 'treatment', namely the consumer out-ofpocket price. In figure 6 this is presented on a daily basis 14 days before and after the reform date. On the vertical axis we have the average out-of-pocket price per prescription redeemed. The new reimbursement scheme causes the average out-of-pocket price to jump up roughly $100 \%$.

\section{FIGURE 6}

AVERAGE OUT-OF-POCKET PRICE PER PRESCRIPTION - PENICILLIN

+/- 14 DAYS ON EACH SIDE OF REFORM DATE

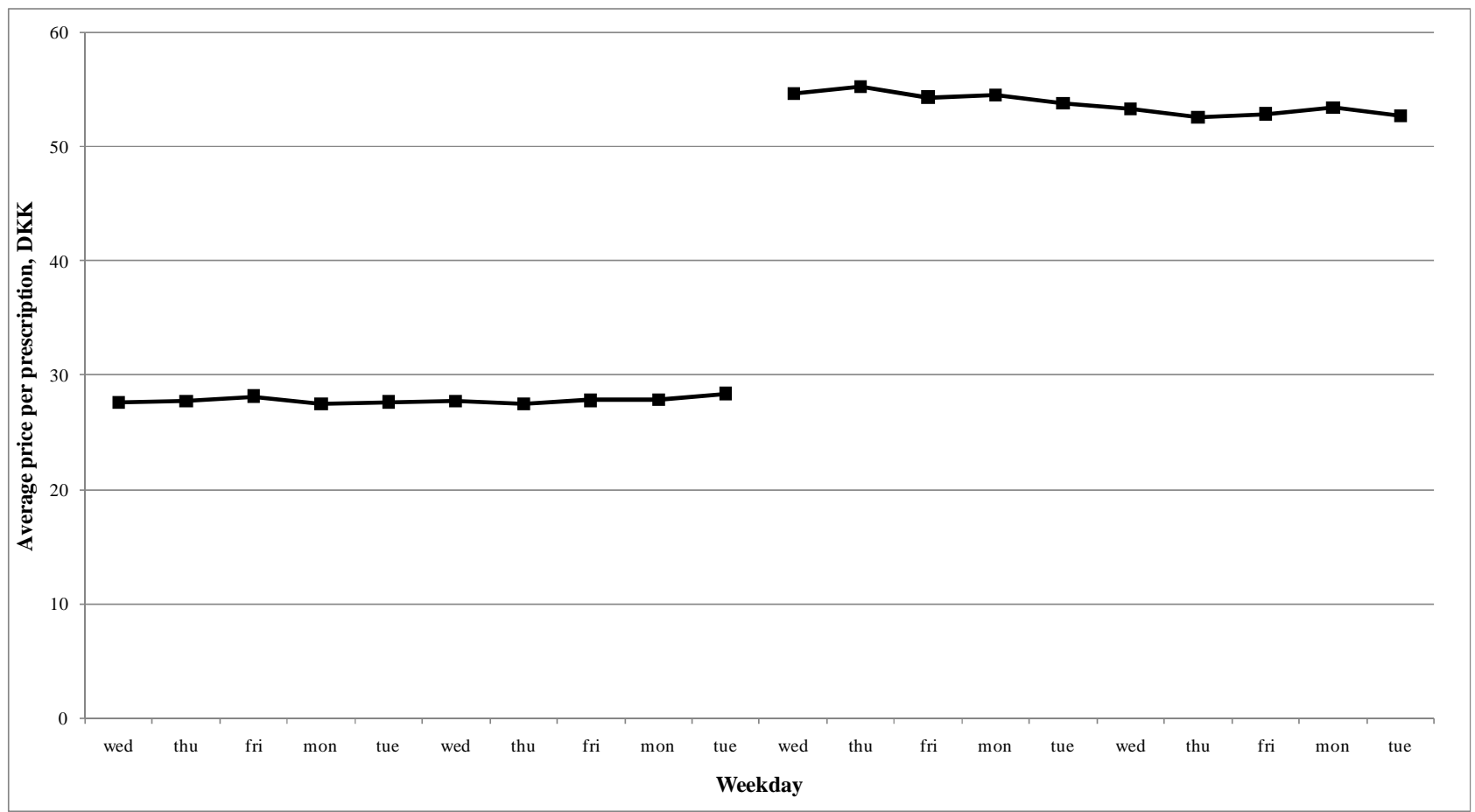

Note: Statisics Denmark, 20\% random sample. Average out-of-pocket payment per prescription redeemed. 
Figure 7 presents the empirical propensities to purchase penicillin on a weekly basis before and after the reform. There are 14 days on each side of the reform date. However the results from Saturdays and Sundays are not plotted as they contaminate the overall picture (there are very few purchases on weekends, a graph with the weekends included is placed in Appendix C). The propensities are marginal effects from a probit estimation with dummies for each individual day, with the first day (a Wednesday) omitted. That is, the propensities should be seen as deviations from this day. We see that the propensity to purchase penicillin peaks on Mondays which seems only natural since GPs are usually closed during the weekends, so people who become sick in the weekends have to wait till the coming Monday to get a prescription (if they are very sick, they can go to see at doctor from the emergency service to get a prescription). The purchase propensities on the remaining weekdays do not seem to be statistically significantly different from each other. More importantly, an eyeball test shows that there is a downward shift in the propensity to purchase in the post-reform period.

We now turn to the estimation of the model outlined in equation (1.2) in section 5. Our parameter of interest, $\beta_{1}$, which measures the jump in the propensity caused by the increase in price, will be estimated using different specifications that controls for the daily variation we observe in figure 7. Each individual is observed each day in the time period of interest. Estimation is carried out using a pooled probit ${ }^{9}$ model with individual level clustering. As a sensitivity check, estimation is performed using one and two weeks on each side of the reform date, respectively. The results are reported in table 9.

\footnotetext{
${ }^{9}$ A linear probability model yields almost identical results.
} 
FIGURE 7

PURCHASE PROPENSITY - PENICILLIN

+/- 14 DAYS ON EACH SIDE OF REFORM DATE

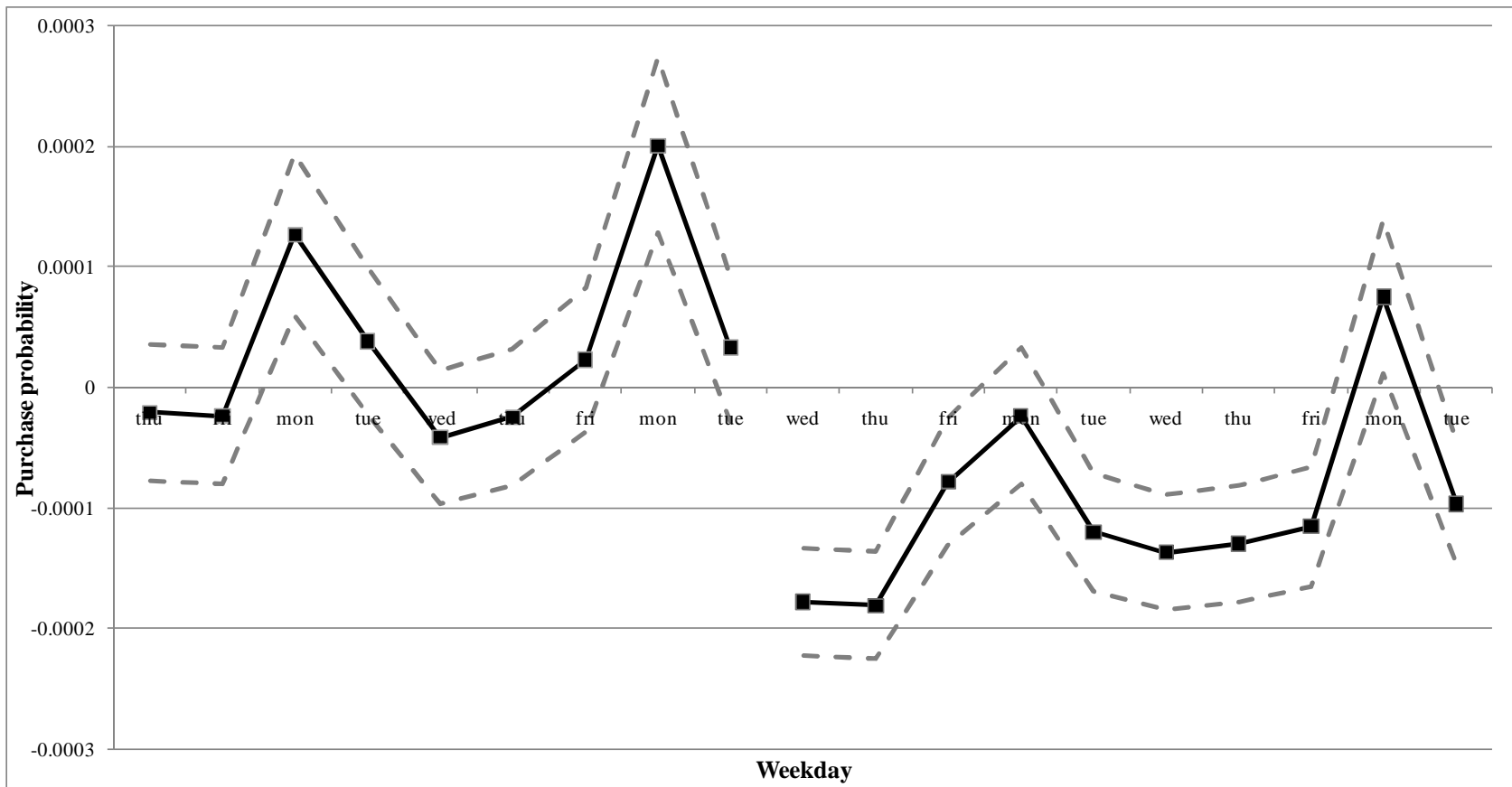

Note: Statisics Denmark, 20\% random sample. Probit estimation of daily purchase propensity around March 12000 , w. first Wednesday omitted. Dotted line is $95 \%$ confidence band.

As we can see in table 9, the coefficient to the reform indicator is negative and highly statistically significant, suggesting a drop in the propensity to purchase. In order to quantify the drop in the propensity, I have reported an elasticity measure evaluated at the pre-policy out-of-pocket price. Using two weeks on each side of the reform date yields price elasticities in the range -.21 to -.30. The results are not very sensitive to whether we estimate with one or two weeks on each side. 
TABLE 9

PROBIT MARGINAL EFFECTS - PENICILLIN

\begin{tabular}{c|ccccc}
\hline \hline \multicolumn{3}{c}{+ - 2 Weeks } & \multicolumn{2}{c}{$+/-1$ Week } \\
\hline$I[t \geq 0]$ & $\mathbf{- 0 . 1 8 1}$ & $\mathbf{- 0 . 1 9 9}$ & $\mathbf{- 0 . 1 3 9}$ & $\mathbf{- 0 . 2 3 2}$ & $\mathbf{- 0 . 1 6 1}$ \\
& $(0.02)$ & $(0.018)$ & $(0.009)$ & $(0.027)$ & $(0.013)$ \\
TREND & $\mathbf{0 . 0 0 3}$ & $\mathbf{0 . 0 0 4}$ & - & $\mathbf{0 . 0 1 0}$ & - \\
& $(0.001)$ & $(0.001)$ & - & $(0.003)$ & - \\
WEEKEND & - & $\mathbf{- 0 . 6 1 2}$ & $\mathbf{- 0 . 6 0 9}$ & $\mathbf{- 0 . 6 0 7}$ & $\mathbf{- 0 . 5 9 9}$ \\
& - & $(0.012)$ & $(0.012)$ & $(0.018)$ & $(0.017)$ \\
MON & - & $\mathbf{0 . 1 6 2}$ & $\mathbf{0 . 1 7 6}$ & $\mathbf{0 . 1 4 3}$ & $\mathbf{0 . 1 7 5}$ \\
& - & $(0.012)$ & $(0.012)$ & $(0.02)$ & $(0.017)$ \\
ALL WEEK & $\mathrm{YES}$ & $\mathrm{NO}$ & $\mathrm{NO}$ & $\mathrm{NO}$ & $\mathrm{NO}$ \\
DAYS & & & & & \\
\# Obs. & $23,004,604$ & $23,004,604$ & $23,004,604$ & $11,502,302$ & $11,502,302$ \\
\hline Ep & $\mathbf{- 0 . 2 7}$ & $\mathbf{- 0 . 3 0}$ & $\mathbf{- 0 . 2 1}$ & $\mathbf{- 0 . 3 3}$ & $\mathbf{- 0 . 2 3}$ \\
\hline
\end{tabular}

Note: Marginal effects from probit estimation of the probability of purchase during

a given day with two and one week on each side of the reform date. S.E. in ( ).

Clustering on person ID. Bold indicates significance at the 5\% level. All coefficients

are multiplied by a factor 1,000 .

To make sure what the results are not driven by some peculiar time-effects, I carry out a falsification test whereby I redo the above analysis in exactly the same way, but with an artificial reform date, March 1 1999. That is, I consider two weeks on each side of March 1 1999. In this period, penicillin was subject to the $50 \%$ subsidy, so we expect to see a flat out-of-pocket price profile over the period. A graph depicting the average out-of-pocket price for the period is available in figure 8 . We see that the price is a little lower than the pre-reform price in figure 6 , but otherwise the price is constant.

The propensities equivalent to those in figure 7 are plotted in figure 9 . In figure 9 , the reference day left out is a Monday. Again, sales peak at Mondays. Notice how the point estimate for the last Monday in February is the largest, just as in the graph for the reform year. A potential worry about figure 7 is that the peak this particular Monday might have something to do with stocking up, but we see the same pattern in 1999. In the reform year, the two Mondays in the pre-reform period (two last Mondays in February) are not statistically significantly different. However they are different in 1999. There is no visible jump in the propensity over the two periods. Notice that the confidence bands for last weekday (a Friday) in the 'pre-reform' period is overlapping with the first weekday (a Monday) in the 'post-reform' period. Although there does not seem to be any jump in the 
propensity, there seems to be a negative trend. The specifications estimated for the reform year are also performed, and the results at brought in table 10.

FIGURE 8

FALSIFICATION TEST: AVERAge OUT-OF-POCKET PRICE PER PRESCRIPTION - PENICILLIN +/- 14 DAYS ON EACH SIDE OF MARCH $1^{\text {st }} 1999$

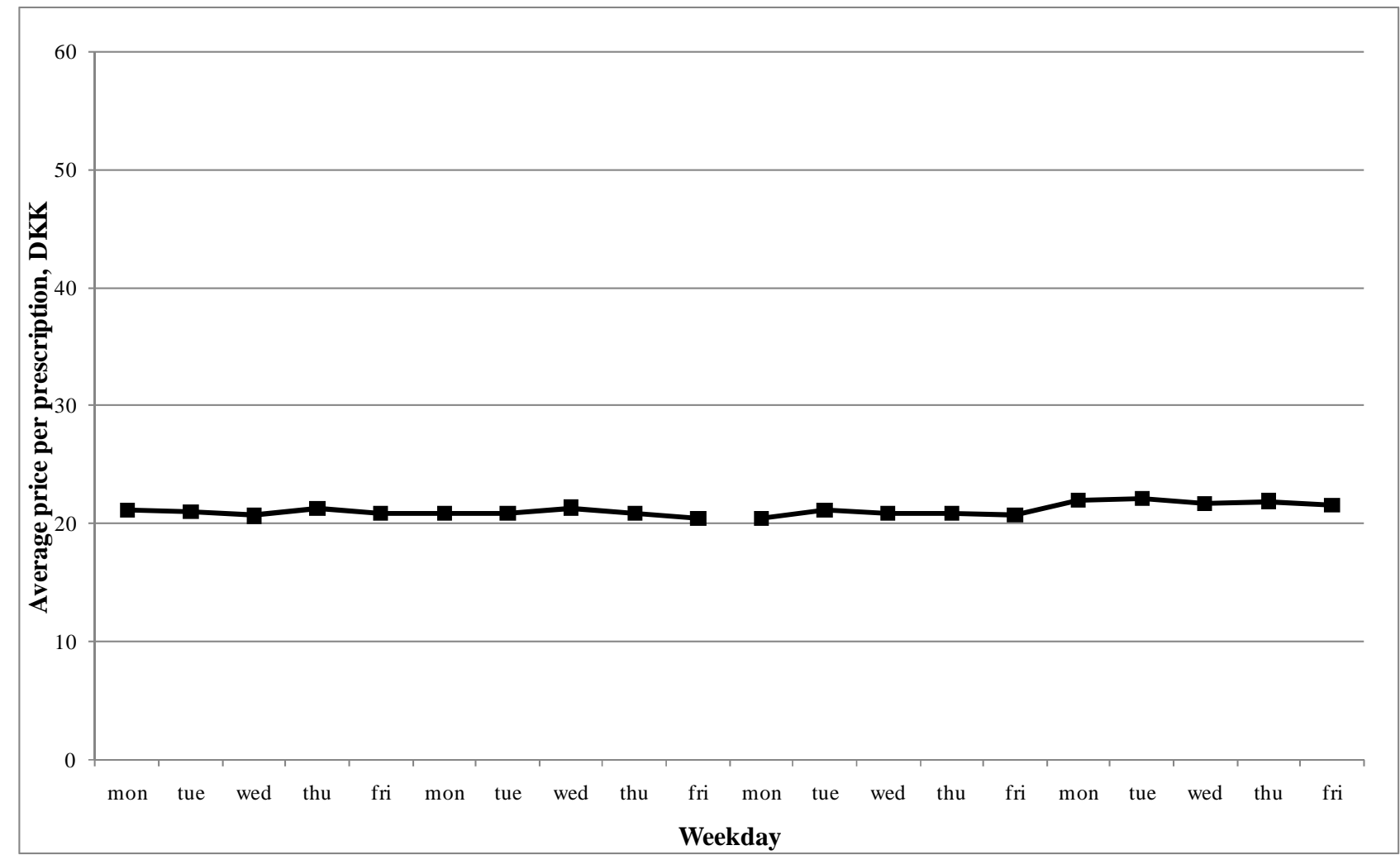

Note: Statistics Denmark, 20\% random sample. Average out-of-pocket payment per prescription redeemed around March 1 1999. Prices are in 1999 (DKK). 
FIGURE $9^{\text {a }}$

FALSIFICATION TEST: PURCHASE PROPENSITY - PENICILLIN +/- 14 DAYS ON EACH SIDE OF MARCH $1^{\text {st }} 1999$

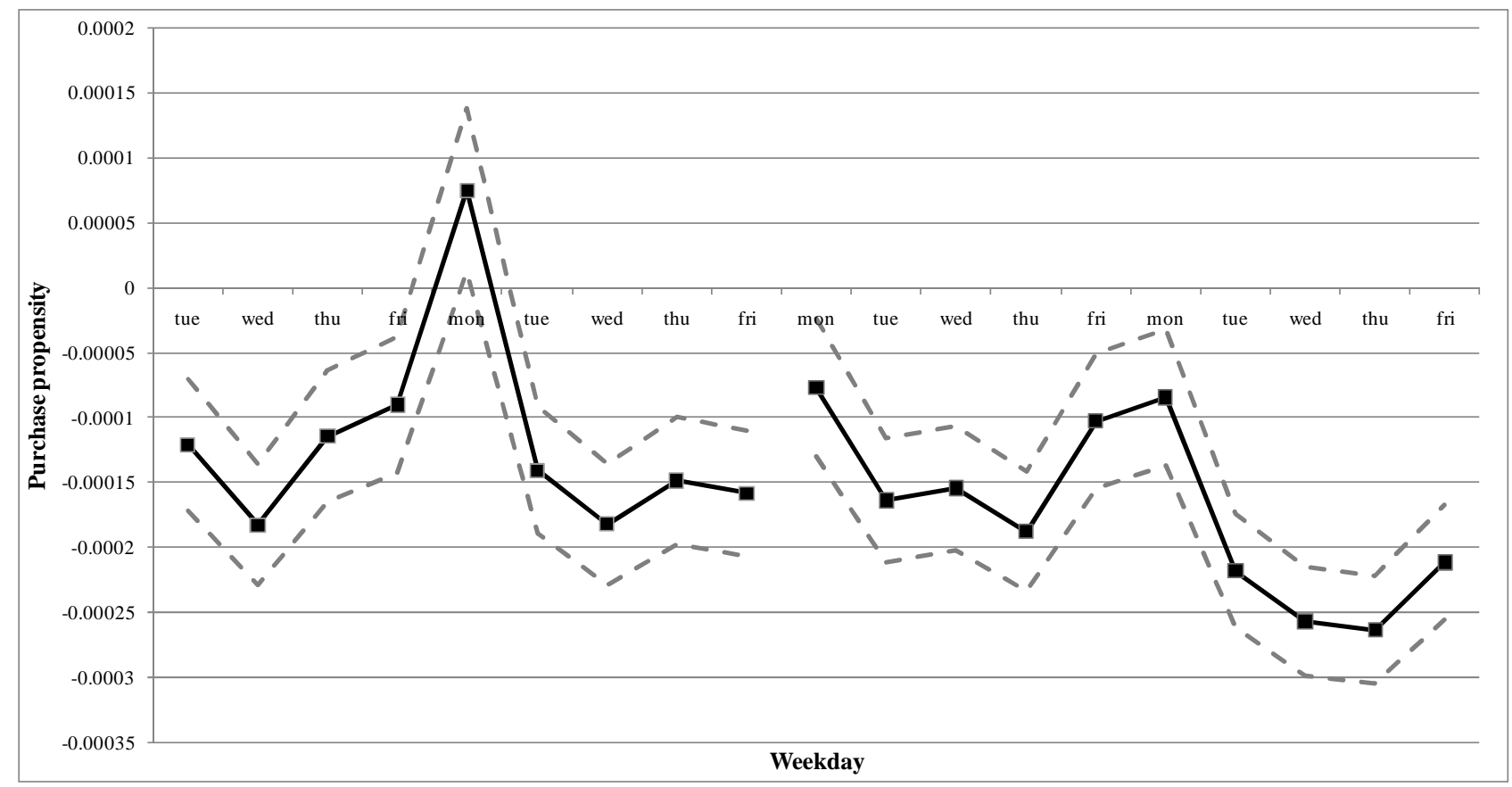

Note: Statistics Denmark, 20\% random sample. Probit estimation of daily purchase propensity around March 12000 , w. first Wednesday omitted. Dotted line is $95 \%$ confidence band.

The point estimates of our parameter of interest, the coefficient to the reform-indicator, are very small for the falsification test, compared to the estimates for the reform year, and insignificant in 3 out of 5 specifications. The specifications where the estimates are significant are those without a time trend included, so the downward time trend we saw in figure 8 is plausibly being caught by the reform-dummy in these cases. Estimation using a difference-in-difference setup with the population in the falsification test as control group yields very similar results to those in table 9 and are therefore not reported. 
TABLE 10

PROBIT MARgINAL EFFECTS - FALSIFICATION TEST PENICILLIN

\begin{tabular}{c|ccccc}
\hline \hline \multicolumn{3}{c}{$+/$ - 2 Weeks } & \multicolumn{2}{c}{$+/$ 1 Week } \\
\hline I[ $t \geq 0]$ & 0.018 & 0.009 & $\mathbf{- 0 . 0 8 5}$ & -0.042 & $\mathbf{- 0 . 0 3 3}$ \\
& $(0.022)$ & $(0.021)$ & $(0.01)$ & $(0.054)$ & $(0.014)$ \\
TREND & $\mathbf{- 0 . 0 0 7}$ & $\mathbf{- 0 . 0 0 7}$ & - & 0.001 & - \\
& $(0.001)$ & $(0.001)$ & - & $(0.008)$ & - \\
WEEKEND & - & $\mathbf{- 0 . 7 0 0}$ & $\mathbf{- 0 . 7 1 4}$ & $\mathbf{- 0 . 7 4 6}$ & $\mathbf{- 0 . 7 4 3}$ \\
& - & $(0.014)$ & $(0.013)$ & $(0.027)$ & $(0.019)$ \\
MON & - & $\mathbf{0 . 1 6 9}$ & $\mathbf{0 . 1 8 9}$ & $\mathbf{0 . 2 0 0}$ & $\mathbf{0 . 1 9 6}$ \\
& - & $(0.014)$ & $(0.013)$ & $(0.028)$ & $(0.019)$ \\
ALL WEEK & $\mathrm{YES}$ & $\mathrm{NO}$ & $\mathrm{NO}$ & $\mathrm{NO}$ & $\mathrm{NO}$ \\
DAYS & & & & & \\
\# Obs. & $22,984,892$ & $22,984,892$ & $22,984,892$ & $11,492,446$ & $11,492,446$ \\
\hline
\end{tabular}

Note: Marginal effects from probit estimation of the probability of purchase during a given day with two and one week on each side of the reform date. S.E. in ( ).Clustering on person ID. Bold indicates significance at the $5 \%$ level. All coefficients are multiplied by a factor 1,000 .

As a last sensitivity check the individual level analysis on penicillin is split down by income. I define low/high income as individuals having an income below/above the median income in the calendar year of 1999. The results shows (in most specifications) that people with low income are more price responsive than people with high income, see table 10. These findings are consistent with Simonsen et al. (2010), even though this paper exploits a completely different source of price variation. It is possible that these findings are related to membership of the private insurance company "Danmark": If the probability of membership is positively correlated with income, the lower price responses by high income consumers may just reflect this. However, the price elasticities for penicillin reported in this paper are generally in line with the lower estimates in the literature (see section 2).

To sum up, the analysis shows that the drug reimbursement reform had a positive effect on the consumer's out-of-pocket payment and that this was associated with considerable declines in utilization of both insulin and penicillin. For insulin, the decline in utilization took place on both the intensive and extensive margin that is, some opted completely out of treatment and those still in treatment lowered their consumption. The latter is consistent with what is termed 'drug holidays' in the medical literature on non-compliance, i.e., that people stretch a given amount of medication to cover more days than it has been prescribed for. Alternatively, doctors might have internalized the cost of the medications that their patients need and adopted a more efficient prescribing pattern. For 
penicillin, the analysis suggests a decline on the extensive margin only. The estimated price responses should be seen as net of private insurance.

TABLE 11

PROBIT MARGINAL EFFECTS - PENICILLIN - BY INCOME

\begin{tabular}{|c|c|c|c|c|c|c|c|c|c|c|}
\hline & \multicolumn{5}{|c|}{ Low Income } & \multicolumn{5}{|c|}{ High Income } \\
\hline & \multicolumn{3}{|c|}{$+/-2$ Weeks } & \multicolumn{2}{|c|}{ +/- 1 Week } & \multicolumn{3}{|c|}{$+/-2$ Weeks } & \multicolumn{2}{|c|}{ +/- 1 Week } \\
\hline \multirow[t]{2}{*}{$I[t \geq 0]$} & -0.210 & -0.220 & -0.142 & -0.235 & -0.178 & -0.151 & -0.178 & -0.135 & -0.228 & -0.144 \\
\hline & $(0.028)$ & $(0.026)$ & $(0.013)$ & $(0.037)$ & $(0.018)$ & $(0.028)$ & $(0.026)$ & $(0.013)$ & $(0.038)$ & $(0.018)$ \\
\hline \multirow[t]{2}{*}{ TREND } & 0.005 & 0.005 & - & 0.008 & - & 0.001 & 0.003 & - & 0.012 & - \\
\hline & $(0.002)$ & $(0.002)$ & - & $(0.005)$ & - & $(0.002)$ & $(0.002)$ & - & $(0.005)$ & - \\
\hline \multirow[t]{2}{*}{ WEEKEND } & - & -0.663 & -0.659 & -0.659 & -0.653 & - & -0.562 & -0.559 & -0.555 & -0.545 \\
\hline & - & $(0.018)$ & $(0.018)$ & $(0.026)$ & $(0.025)$ & - & $(0.017)$ & $(0.017)$ & $(0.024)$ & $(0.024)$ \\
\hline \multirow[t]{2}{*}{$M O N$} & - & 0.151 & 0.169 & 0.141 & 0.168 & - & 0.174 & 0.184 & 0.143 & 0.182 \\
\hline & - & $(0.018)$ & $(0.017)$ & $(0.027)$ & $(0.024)$ & - & (0.018) & (0.018) & $(0.028)$ & $(0.025)$ \\
\hline $\begin{array}{c}A L L \text { WEEK } \\
\text { DAYS }\end{array}$ & YES & NO & NO & NO & NO & YES & NO & NO & NO & NO \\
\hline \#Obs. & $11,474,960$ & $11,474,960$ & $11,474,960$ & $5,737,480$ & $5,737,480$ & $11,529,728$ & $11,529,728$ & $11,529,728$ & $5,764,864$ & $5,764,864$ \\
\hline$\varepsilon_{\mathrm{p}}$ & -0.30 & -0.32 & -0.21 & -0.32 & -0.24 & -0.20 & -0.24 & -0.18 & -0.35 & -0.22 \\
\hline
\end{tabular}

Note: Marginal effects from probit estimation of the probability of purchase during a given day with two and one week on each side of the reform date. S.E. in ( ). Clustering on person ID. Bold indicates significance at the $5 \%$ level. All coefficients are multiplied by a factor 1,000 . Low/high income is defined as people with income below/above median income.

\section{Conclusion}

This paper analyzes the effect of increased co-payments on two different prescription drugs, insulin and penicillin, caused by a reform of the reimbursement scheme for the general public in Denmark. I show that reliable estimates of the price elasticity of demand can be difficult to uncover if the source of price variation used is (announced) changes in consumer co-payment. Patients in treatment with drugs that maintain chronic conditions, such as insulin, are much more likely to stockpile on their medications if they foresee future price (co-payment) increases. This fact leads us to overestimate the price response of the consumer. Removing observations close to the date of the price change reduces this bias, but consumers may have stockpiled to a degree that even this strategy is not sufficient. Further, the new co-payment system had spillover effects on the consumption of other essential drugs for people treated with insulin. It is possible that these results are also driven by stockpiling, even though I argue that stockpiling of other drugs might not be optimal. 
For penicillin, that treats an acute and non-chronic condition, stockpiling is arguably much less likely. Using a regression discontinuity design in the time dimension, I find the price elasticity of demand to be in the interval -.18 - -.35. The price response was found to be larger for the lower part of the income distribution. The size of the estimated price response is comparable to the existing literature outlined in section 2. That the demand for low income individuals is more price elastic is consistent with the findings in Simonsen et al. (2010), despite that this paper uses a completely different source of price variation.

Analyzing the phenomenon of stockpiling more detailed would call for a structural dynamic approach which also incorporates the non-linear pricing consumers face after the reform. It is plausible that one would see similar stockpiling patterns under the new subsidy scheme as people get to the end of their individual subsidy years. This type of behavior points to inherent inefficiencies of such subsidy schemes. This is, however, not within the scope of this paper and is left as a point of future research.

\section{Literature}

Chandra, A., J. Gruber, J. and R. McKnight (2010): "Patient Cost - Sharing and Hospitalization Offsets in the Elderly", American Economic Review 100, 193-213.

Contoyannis, P., J. Hurley, P. Grootendorst, S. Jeon and R. Tamblyn (2005): "Estimating the price elasticity of expenditure for prescription drugs in the presence of non-linear price schedules: an illustration from Quebec, Canada", Health Economics 14, 909-923.

Duggan, M., F. Scott Morton: "The Effect of Medicare Part D on Pharmaceutical Prices and Utilization ", American Economic Review 100, 590-607. 
Hahn, J., P. Todd, and W. van der Klaauw (2001): "Identification and Estimation of Treatment Effects with a Regression-Discontinuity Design”, Econometrica 69, 201-209.

Hendel, I., A. Nevo (2006): "Measuring the Implications of Sales and Consumer Inventory Behavior," Econometrica, 74(6), 1637- 1673.

Hendel, I., A. Nevo (2009): “A Simpel Model of Demand Anticipation”, Mimeo: http://econ$\underline{\text { www.mit.edu/files/4516 }}$

Honoré, Bo E. (1992): "Trimmed LAD and Least Squares Estimation of Truncated and Censored Regression Models with Fixed Effects”, Econometrica, Vol. 60, 533-565.

Imbens, G. W., and T. Lemieux (2008): "Regression Discontinuity Designs: A Guide to Practise", Journal of Econometrics 142, 615-635.

Keeler, E. B., J. P. Newhouse, and C. E. Phelps (1977): "Deductibles and the Demand for Medical Care Services: the Theory of a Consumer Facing a Variable Price Schedule under Uncertainty", Econometrica 45, 641-655.

Lexchin, J., and P. Grootendorst (2004): "Effects of Prescription Drug User Fees on Drugs and Health Services Use and on Health Status in Vulnerable Populations: A Systematic Review of the Evidence", International Journal of Health Services 34, 101-122.

Manning, W. G., J. P. Newhouse, N. Duan, E. B. Keeler, A. Leibowitz, and M. S. Marquis (1987): Health Insurance and the Demand for Medical Care: Evidence from a Randomized Experiment. The American Economic Review 77, 251-277.

Newhouse, J. (1993): Free for All: Lessons from the RAND Health Insurance Experiment. Cambridge, MA. Harvard University Press.

Pavnic, N. (2002): "Do Pharmaceutical Prices Respond to Potential Patient Out-of-Pocket Expenses?", RAND Journal of Economics 33, 469-487. 
Simonsen, M., L. Skipper, and N. Skipper (2010): "Price Sensitivity of Demand for Prescription Drugs: Exploiting a Regression Kink Design”, Working Paper.

Tamblyn, R., R. Laprise, J. A. Hanley et al. (2001): Adverse Events Associated with Prescription Drug Cost-Sharing among Poor and Elderly Persons, Journal of the American Medical Association $285,421-429$. 


\section{Appendix A}

Example of an ATC-code. Metformin, used in diabetes treatment.

\section{Example Of ATC-Code}

\begin{tabular}{ll}
\hline \hline ATC-Code & A10BA02 \\
\hline A & Alimentary tract and metabolism \\
& (1st level, anatomical main group) \\
Drugs used in diabetes \\
(2nd level, therapeutic subgroup) \\
A10
\end{tabular}

http://www.whocc.no/atcddd/ 


\section{Appendix B}

\section{INSULIN}

Total volume of insulin sold per week by ATC-code. Volumes are standardized with means.

Total Volum (DDD) (stand.)

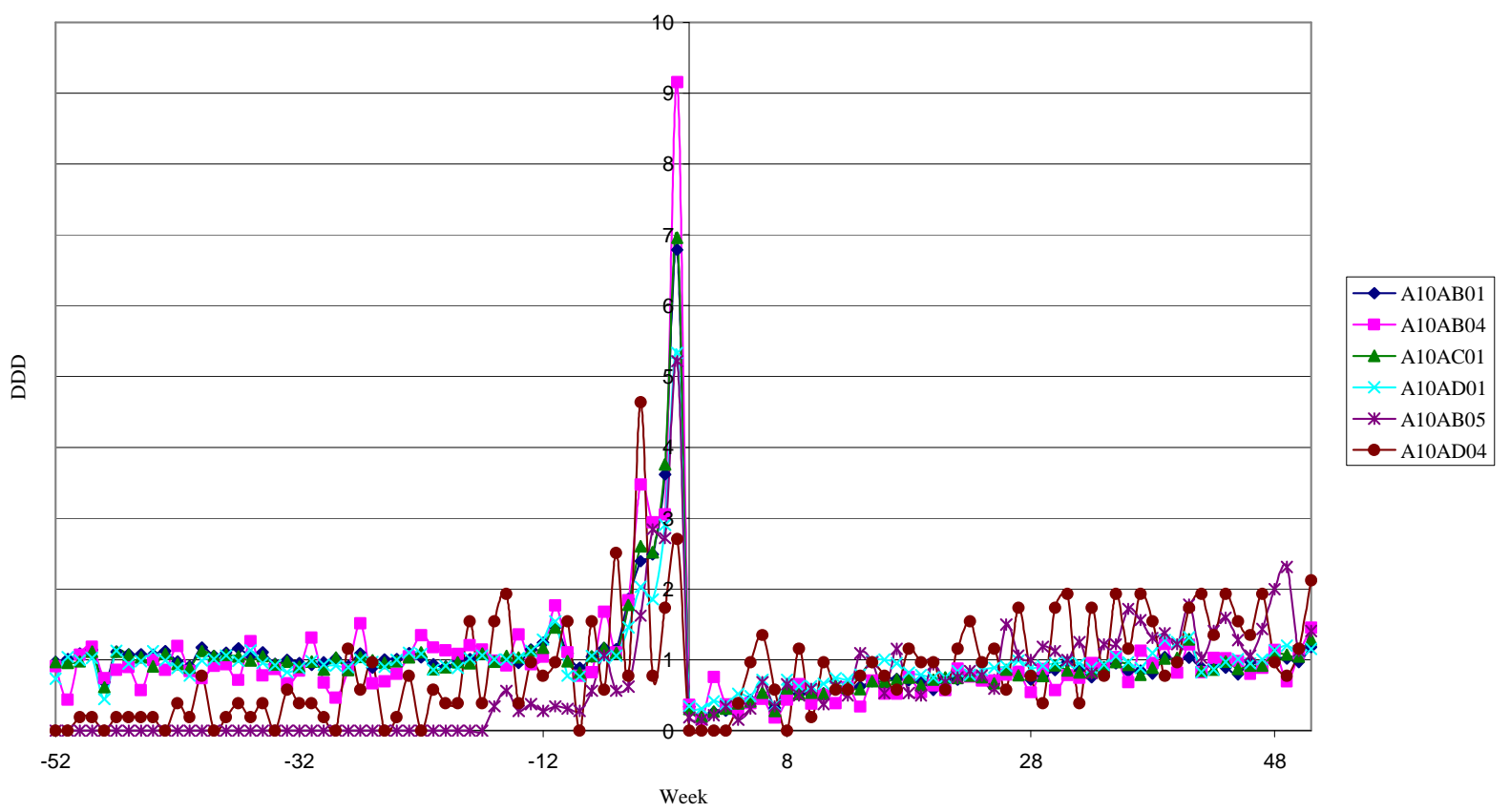

The share of the total market of insulin by ATC-code.

Market Share (DDD)

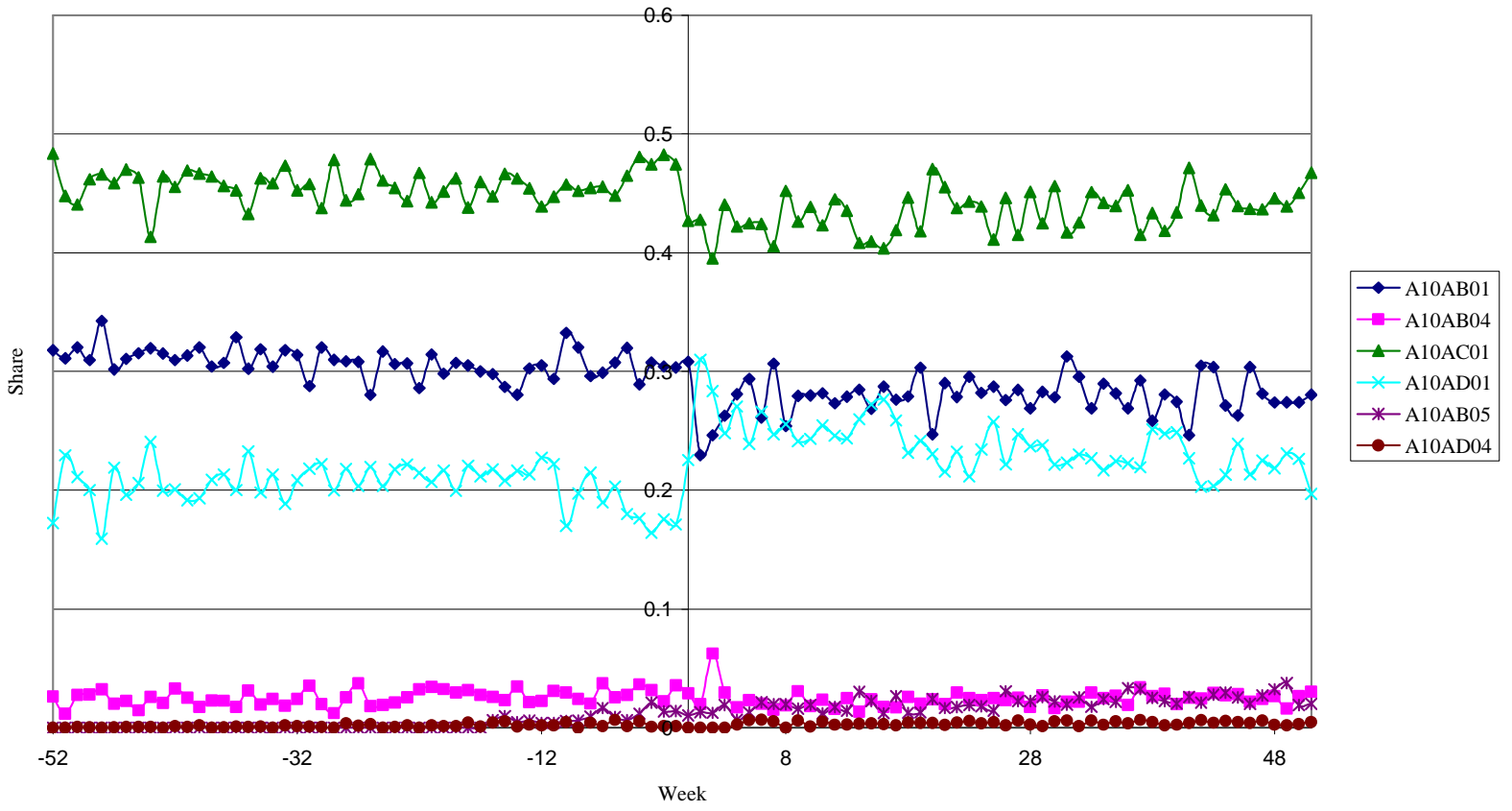


The average total price of insulin per DDD by ATC-code.

Avg. Total Price per DDD (in DKK)

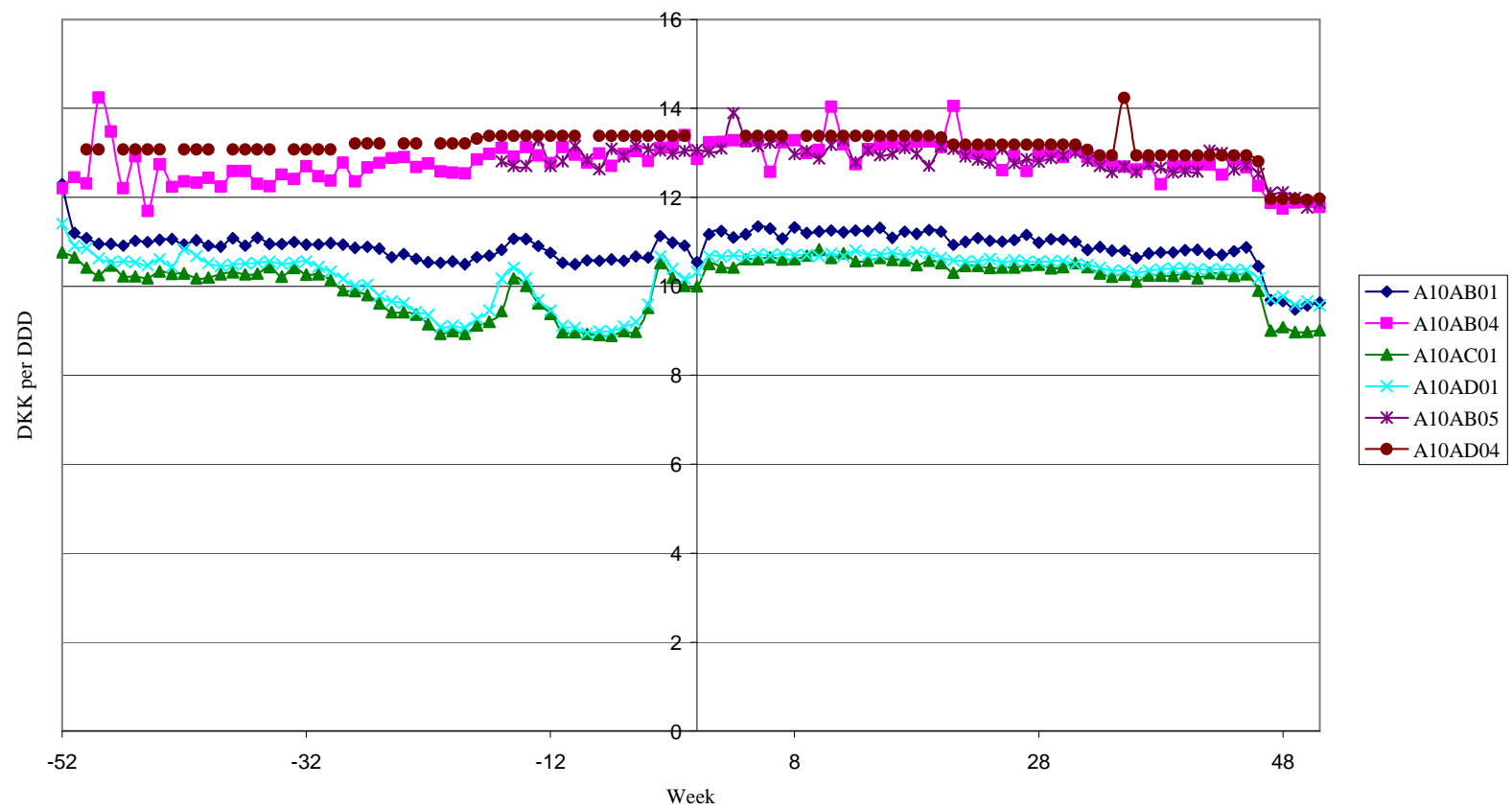

The total number of insulin prescriptions redeemed per week.

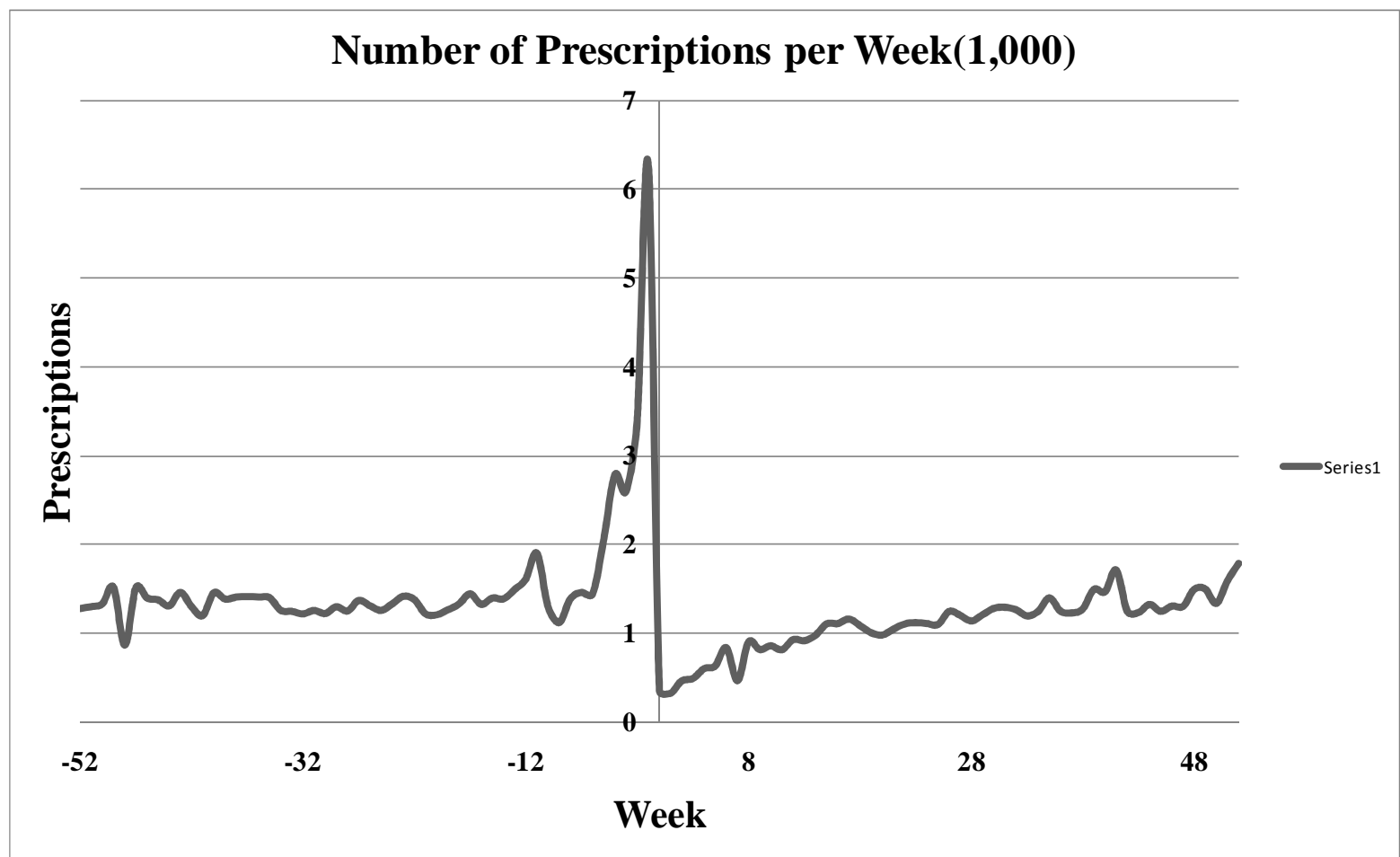

Note: Statistics Denmark. 20\% random sample. Number of filed prescriptions per day, insulin. 
The total number of people buying insulin per week.

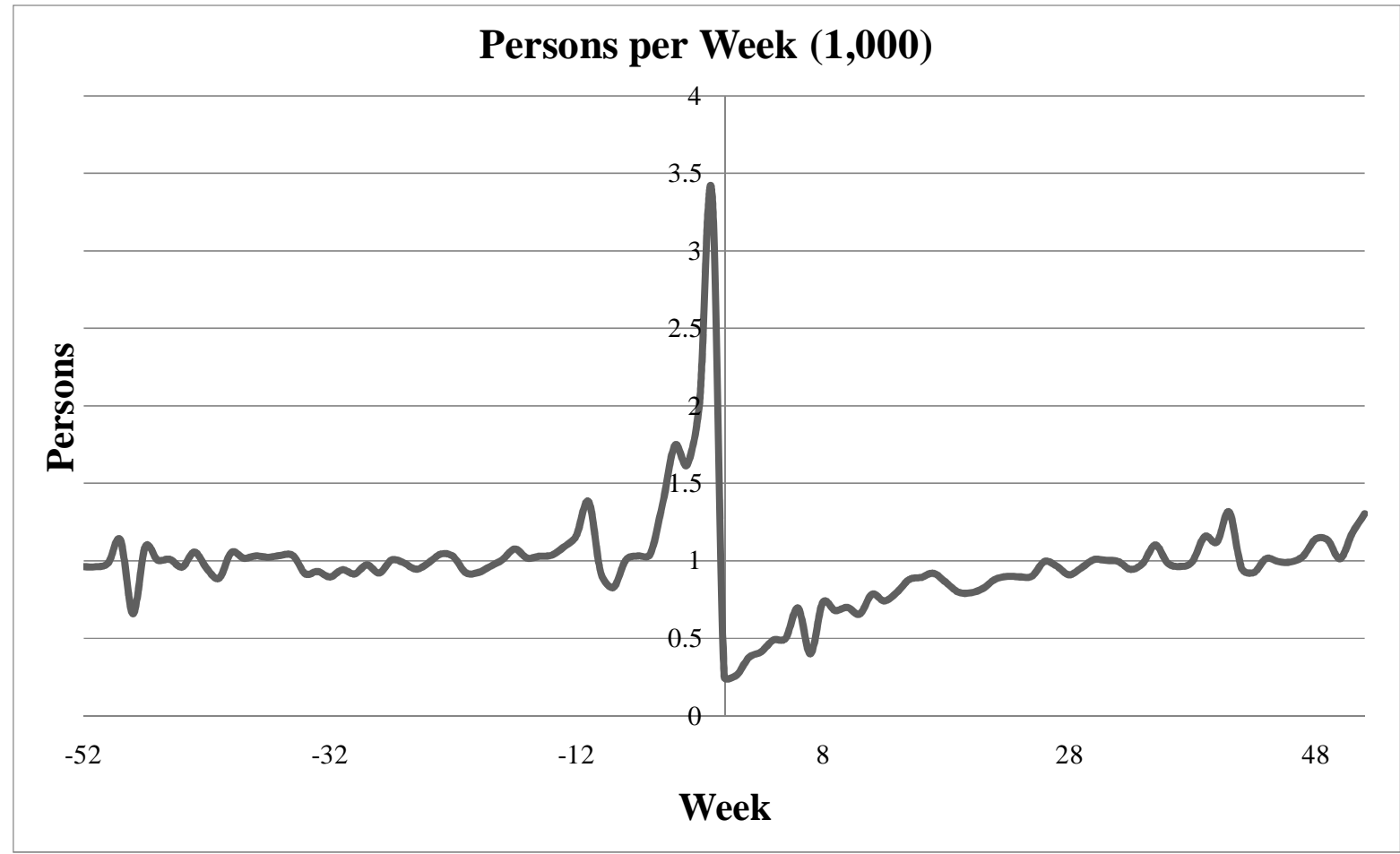

Note: Statistics Denmark. 20\% random sample. Number of persons receiving treatment per day, insulin. 


\section{PENICILLIN}

Total number of penicillin prescriptions redeemed.

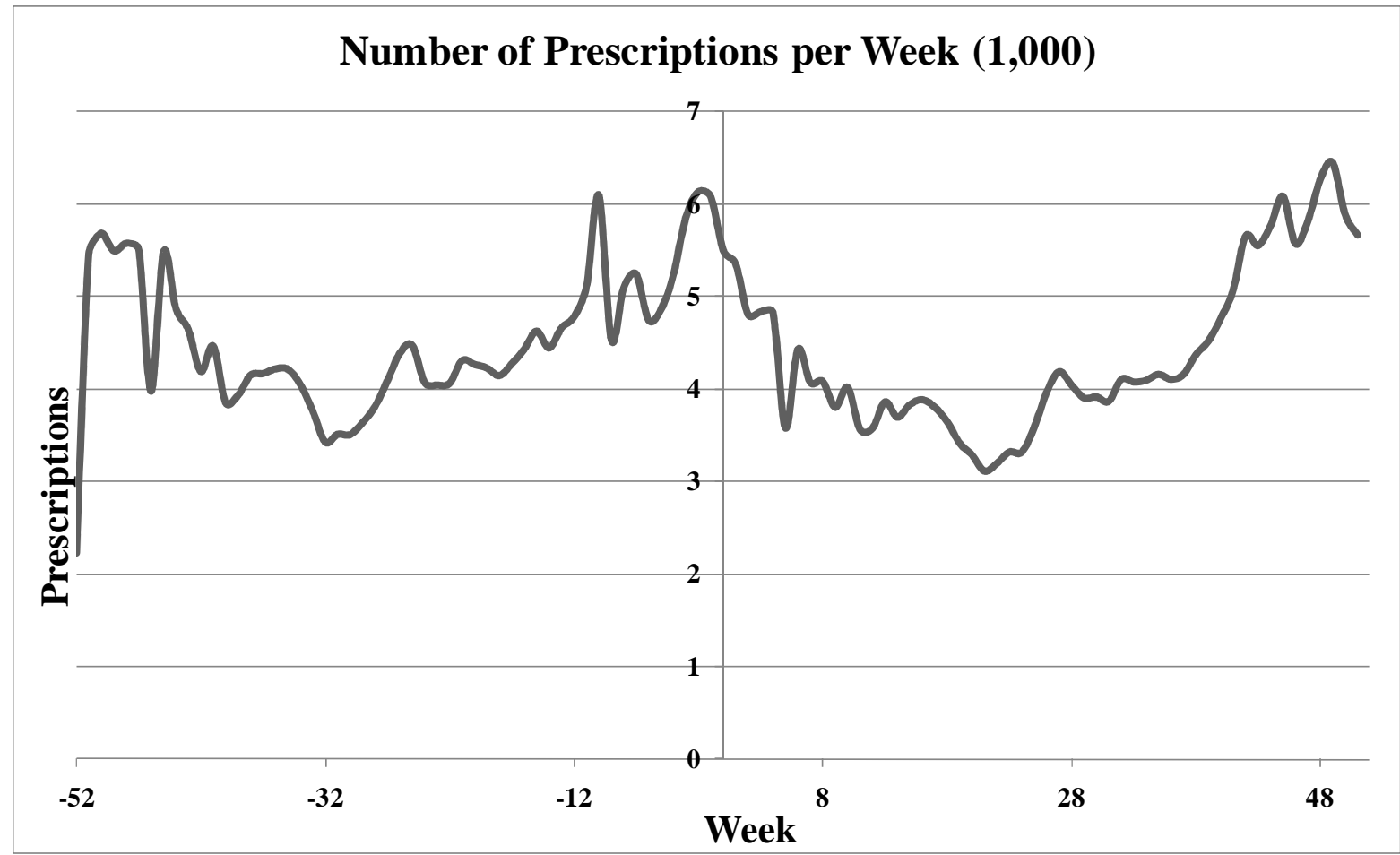

Note: Statistics Denmark. 20\% random sample. Number of prescriptions filed per day, penicillin.

Total number of people buying penicillin.

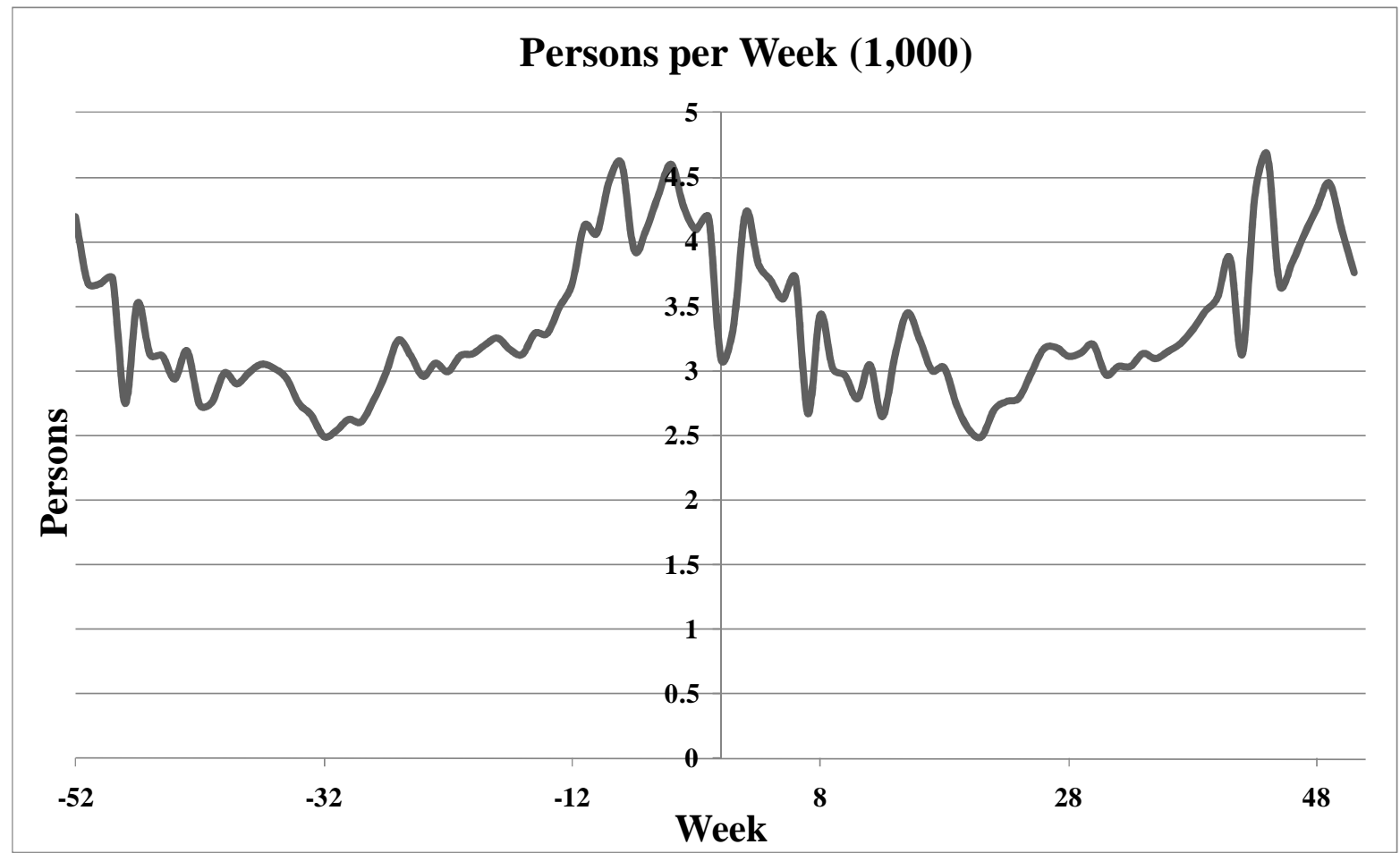

Note: Statistics Denmark. 20\% random sample. Number of persons receiving treatment per day, penicillin. 


\section{Appendix C}

Relative probabilities to purchase penicillin around March 11999 with 14 days on each side of that date.

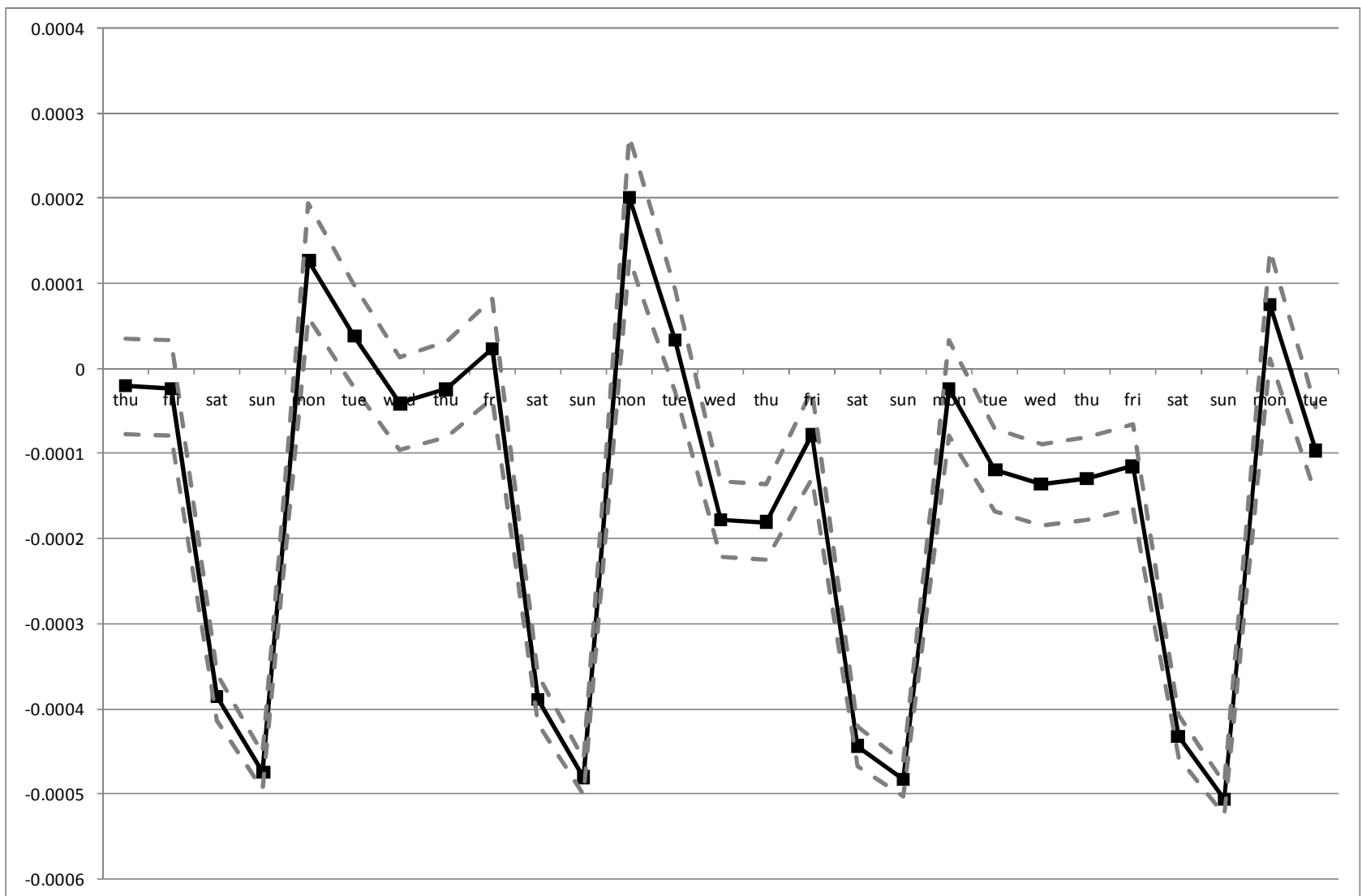

Note: Statistics Denmark, 20\% random sample. Probit estimation of daily purchase propensity around March 12000 , w. first Wednesday omitted. Dotted line is $95 \%$ confidence band. 


\section{Appendix D}

Fixed effect estimation for insulin by income groups.

FIXED EFFECT ESTIMATION - INSULIN - HIGH INCOME

\begin{tabular}{|c|c|c|c|c|c|c|c|c|c|}
\hline & $O O P / D D D$ & & $T P / D D D$ & & OOP/TP & & $D D D$ & PRES & DDD/PRES \\
\hline & \multicolumn{9}{|c|}{ Full sample } \\
\hline$I[t \geq 0]$ & $\begin{array}{c}\mathbf{3 . 5 1} \\
(0.024)\end{array}$ & $\begin{array}{l}\mathbf{1 2 . 1 1} \\
(0.077)\end{array}$ & $\begin{array}{c}\mathbf{0 . 2 8} \\
(0.01)\end{array}$ & $\begin{array}{c}\mathbf{1 . 4 7} \\
(0.039)\end{array}$ & $\begin{array}{c}\mathbf{0 . 3 3} \\
(0.002)\end{array}$ & $\begin{array}{c}\mathbf{1 . 0 8} \\
(0.007)\end{array}$ & $\begin{array}{c}\mathbf{- 4 9 9 . 0 6} \\
(19.50)\end{array}$ & $\begin{array}{c}\mathbf{- 8 . 8 6} \\
(0.346)\end{array}$ & $\begin{array}{c}\mathbf{- 2 . 9 1} \\
(1.122)\end{array}$ \\
\hline TREND & $\begin{array}{l}- \\
-\end{array}$ & $\begin{array}{c}-0.01 \\
(0.010)\end{array}$ & $\begin{array}{l}- \\
-\end{array}$ & $\begin{array}{c}\mathbf{- 0 . 1 9} \\
(0.005)\end{array}$ & $\begin{array}{l}- \\
-\end{array}$ & $\begin{array}{c}0.00 \\
(0.001)\end{array}$ & $\begin{array}{l}\mathbf{7 3 . 8 7} \\
(3.710)\end{array}$ & $\begin{array}{c}\mathbf{0 . 7 4} \\
(0.054)\end{array}$ & $\begin{array}{c}\mathbf{3 . 0 4} \\
(0.151)\end{array}$ \\
\hline$I[t \geq 0] X$ TREND & $\begin{array}{l}- \\
-\end{array}$ & $\begin{array}{c}\mathbf{- 1 . 4 9} \\
(0.016)\end{array}$ & $\begin{array}{l}- \\
-\end{array}$ & $\begin{array}{c}\mathbf{- 0 . 0 7} \\
(0.008)\end{array}$ & - & $\begin{array}{c}\mathbf{- 0 . 1 3} \\
(0.001)\end{array}$ & $\begin{array}{c}\mathbf{- 0 . 8 9} \\
(4.460)\end{array}$ & $\begin{array}{c}\mathbf{0 . 5 0} \\
(0.073)\end{array}$ & $\begin{array}{c}\mathbf{- 2 . 2 4} \\
(0.239)\end{array}$ \\
\hline \#Obs. & 22,523 & 22,523 & 22,523 & 22,523 & 22,523 & 22,523 & 28,912 & 28,912 & 22,523 \\
\hline \multirow[t]{2}{*}{ Mean } & 0.06 & 0.06 & 10.40 & 10.40 & 0.01 & 0.01 & 345.63 & 6.53 & 56.13 \\
\hline & & Sub-sai & - exclud & Ond & on each & O11 & ate & & \\
\hline$I[t \geq 0]$ & $\begin{array}{c}\mathbf{2 . 8 9} \\
(0.021)\end{array}$ & $\begin{array}{c}9.49 \\
(0.101)\end{array}$ & $\begin{array}{c}\mathbf{0 . 1 7} \\
(0.011)\end{array}$ & $\begin{array}{c}\mathbf{1 . 9 0} \\
(0.055)\end{array}$ & $\begin{array}{c}\mathbf{0 . 2 7} \\
(0.002)\end{array}$ & $\begin{array}{c}\mathbf{0 . 8 4} \\
(0.009)\end{array}$ & $\begin{array}{c}\mathbf{- 2 3 0 . 4 7} \\
(21.66)\end{array}$ & $\begin{array}{c}\mathbf{- 3 . 3 9} \\
(0.416)\end{array}$ & $\begin{array}{l}\mathbf{- 7 . 7 1} \\
(1.502)\end{array}$ \\
\hline TREND & - & $\begin{array}{c}0.00 \\
(0.015)\end{array}$ & - & $\begin{array}{c}\mathbf{- 0 . 3 4} \\
(0.008)\end{array}$ & $\begin{array}{l}- \\
-\end{array}$ & $\begin{array}{c}0.00 \\
(0.001)\end{array}$ & $\begin{array}{c}-0.67 \\
(3.671)\end{array}$ & $\begin{array}{c}\mathbf{- 0 . 0 5} \\
(0.071)\end{array}$ & $\begin{array}{c}\mathbf{0 . 4 5} \\
(0.223)\end{array}$ \\
\hline$I[t \geq 0] X$ TREND & - & $\begin{array}{c}\mathbf{- 1 . 0 9} \\
(0.022)\end{array}$ & $\begin{array}{l}- \\
-\end{array}$ & $\begin{array}{c}-0.01 \\
(0.011)\end{array}$ & $\begin{array}{l}- \\
-\end{array}$ & $\begin{array}{c}\mathbf{- 0 . 0 9} \\
(0.002)\end{array}$ & $\begin{array}{c}\mathbf{2 5 . 2 6} \\
(5.081)\end{array}$ & $\begin{array}{c}\mathbf{0 . 3 7} \\
(0.098)\end{array}$ & $\begin{array}{c}\mathbf{0 . 7 2} \\
(0.328)\end{array}$ \\
\hline \#Obs. & 17,396 & 17,396 & 17,396 & 17,396 & 17,396 & 17,396 & 21,684 & 21,684 & 17,396 \\
\hline Mean & 0.06 & 0.06 & 10.46 & 10.46 & 0.01 & 0.01 & 295.62 & 5.96 & 53.35 \\
\hline
\end{tabular}

Note: Statistics Denmark, 20\% random sample. Bold indicates significance at 5\% level. S.E. in (), clustered on person ID, 'Mean' is the sample average of outcome in the pre-policy period. 
FIXED EFFECT ESTIMATION - INSULIN - LOW INCOME

\begin{tabular}{|c|c|c|c|c|c|c|c|c|c|}
\hline & $O O P / D D D$ & & $T P / D D D$ & & $O O P / T P$ & & $D D D$ & PRES & $D D D / P R E S$ \\
\hline & & & & & Full samp & & & & \\
\hline$I[t \geq 0]$ & $\begin{array}{c}\mathbf{2 . 8 5} \\
(0.02)\end{array}$ & $\begin{array}{c}\mathbf{9 . 4 1} \\
(0.064)\end{array}$ & $\begin{array}{c}\mathbf{0 . 3 3} \\
(0.009)\end{array}$ & $\begin{array}{c}\mathbf{1 . 4 2} \\
(0.033)\end{array}$ & $\begin{array}{c}\mathbf{0 . 2 7} \\
(0.002)\end{array}$ & $\begin{array}{c}\mathbf{0 . 8 5} \\
(0.006)\end{array}$ & $\begin{array}{c}-400.61 \\
(17.62)\end{array}$ & $\begin{array}{c}\mathbf{- 7 . 1 5} \\
(0.331)\end{array}$ & $\begin{array}{c}\mathbf{- 3 . 9 3} \\
(1.006)\end{array}$ \\
\hline TREND & $\begin{array}{l}- \\
-\end{array}$ & $\begin{array}{l}-0.02 \\
(0.009)\end{array}$ & $\begin{array}{l}- \\
-\end{array}$ & $\begin{array}{c}\mathbf{- 0 . 2 3} \\
(0.005)\end{array}$ & $\begin{array}{l}- \\
-\end{array}$ & $\begin{array}{l}-0.001 \\
(0.001)\end{array}$ & $\begin{array}{c}\mathbf{7 4 . 0 8} \\
(3.564)\end{array}$ & $\begin{array}{c}\mathbf{0 . 7 6} \\
(0.055)\end{array}$ & $\begin{array}{c}2.99 \\
(0.146)\end{array}$ \\
\hline$I[t \geq 0] X$ TREND & - & $\begin{array}{c}\mathbf{- 1 . 1 4} \\
(0.014)\end{array}$ & - & $\begin{array}{c}\mathbf{- 0 . 0 2} \\
(0.007)\end{array}$ & - & $\begin{array}{l}-\mathbf{- 0 . 1 0 1} \\
(0.001)\end{array}$ & $\begin{array}{l}\mathbf{- 1 3 . 1 3} \\
(4.247)\end{array}$ & $\begin{array}{c}\mathbf{0 . 2 6} \\
(0.074)\end{array}$ & $\begin{array}{c}\mathbf{- 2 . 0 2} \\
(0.221)\end{array}$ \\
\hline \# Obs. & 22,748 & 22,748 & 22,748 & 22,748 & 22,748 & 22,748 & 28,912 & 28,912 & 22,748 \\
\hline Mean & 0.06 & 0.06 & 10.26 & 10.26 & 0.01 & 0.01 & 394.06 & 7.52 & 54.85 \\
\hline & & Sub-sa & e - exclud & one per & on each & ef refol & date & & \\
\hline$I[t \geq 0]$ & $\begin{array}{c}\mathbf{2 . 3} \\
(0.017)\end{array}$ & $\begin{array}{c}\mathbf{6 . 9 9} \\
(0.081)\end{array}$ & $\begin{array}{c}\mathbf{0 . 1 9} \\
(0.011)\end{array}$ & $\begin{array}{c}\mathbf{1 . 8 9} \\
(0.049)\end{array}$ & $\begin{array}{c}\mathbf{0 . 2 2} \\
(0.002)\end{array}$ & $\begin{array}{c}\mathbf{0 . 6 2} \\
(0.008)\end{array}$ & $\begin{array}{c}\mathbf{- 1 6 5 . 6 4} \\
(22.48)\end{array}$ & $\begin{array}{c}\mathbf{- 1 . 7 7} \\
(0.454)\end{array}$ & $\begin{array}{c}\mathbf{- 9 . 0 7} \\
(1.368)\end{array}$ \\
\hline TREND & $\begin{array}{l}- \\
-\end{array}$ & $\begin{array}{c}0.00 \\
(0.012)\end{array}$ & $\begin{array}{l}- \\
-\end{array}$ & $\begin{array}{c}\mathbf{- 0 . 3 8} \\
(0.007)\end{array}$ & - & $\begin{array}{c}0.00 \\
(0.001)\end{array}$ & $\begin{array}{c}\mathbf{8 . 3 2} \\
(3.947)\end{array}$ & $\begin{array}{c}0.14 \\
(0.078)\end{array}$ & $\begin{array}{c}\mathbf{0 . 4 9} \\
(0.211)\end{array}$ \\
\hline$I[t \geq 0] X$ TREND & - & $\begin{array}{c}-0.77 \\
(0.018)\end{array}$ & $\begin{array}{l}- \\
-\end{array}$ & $\begin{array}{c}\mathbf{0 . 0 4} \\
(0.011)\end{array}$ & - & $\begin{array}{c}\mathbf{- 0 . 0 7} \\
(0.002)\end{array}$ & $\begin{array}{c}9.35 \\
(5.309)\end{array}$ & $\begin{array}{c}-0.02 \\
(0.107)\end{array}$ & $\begin{array}{c}\mathbf{0 . 9 7} \\
(0.304)\end{array}$ \\
\hline \# Obs. & 17,400 & 17,400 & 17,400 & 17,400 & 17,400 & 17,400 & 21,684 & 21,684 & 17,400 \\
\hline Mean & 0.07 & 0.07 & 10.34 & 10.34 & 0.01 & 0.01 & 345.29 & 6.99 & 52.28 \\
\hline
\end{tabular}

Note: Statistics Denmark, 20\% random sample. Bold indicates significance at 5\% level. S.E. in (), clustered on person ID, 'Mean' is the sample average of outcome in the pre-policy period.

Fixed effect estimation of consumption of other drugs by income groups.

FIXED EFFECT ESTIMATION - INSULIN - CONSUMPTION OF OTHER DRUGS - HIGH INCOME

\begin{tabular}{|c|c|c|c|c|c|c|c|c|c|c|c|}
\hline & $O O P / D D D$ & & $T P / D D D$ & & $O O P / T P$ & & $D D D$ & PRES & DDD/PRES & ESSENTIAL & LESS ESS. \\
\hline & \multicolumn{11}{|c|}{ Full sample } \\
\hline$I[t \geq 0]$ & $\begin{array}{c}\mathbf{1 . 1 1} \\
(0.187)\end{array}$ & $\begin{array}{c}\mathbf{9 . 2 6} \\
(0.704)\end{array}$ & $\begin{array}{c}-0.61 \\
(0.521)\end{array}$ & $\begin{array}{c}2.56 \\
(1.967)\end{array}$ & $\begin{array}{c}\mathbf{0 . 0 8} \\
(0.004)\end{array}$ & $\begin{array}{c}\mathbf{0 . 9 1} \\
(0.011)\end{array}$ & $\begin{array}{c}\mathbf{- 3 5 6 . 6 1} \\
(21.82)\end{array}$ & $\begin{array}{c}-4.48 \\
(0.243)\end{array}$ & $\begin{array}{l}\mathbf{- 1 0 . 6 6} \\
(2.024)\end{array}$ & $\begin{array}{c}\mathbf{- 0 . 6 6} \\
(0.060)\end{array}$ & $\begin{array}{c}\mathbf{- 0 . 8 4} \\
(0.076)\end{array}$ \\
\hline TREND & $\begin{array}{l}- \\
-\end{array}$ & $\begin{array}{c}\mathbf{- 0 . 2 5} \\
(0.115)\end{array}$ & $\begin{array}{l}- \\
-\end{array}$ & $\begin{array}{c}\mathbf{- 0 . 9 1} \\
(0.321)\end{array}$ & $\begin{array}{l}- \\
-\end{array}$ & $\begin{array}{c}\mathbf{- 0 . 0 1} \\
(0.002)\end{array}$ & $\begin{array}{c}\mathbf{8 5 . 9 6} \\
(4.596)\end{array}$ & $\begin{array}{c}\mathbf{1 . 0 7} \\
(0.056)\end{array}$ & $\begin{array}{c}\mathbf{1 . 3 4} \\
(0.331)\end{array}$ & $\begin{array}{c}\mathbf{0 . 0 9} \\
(0.008)\end{array}$ & $\begin{array}{c}\mathbf{0 . 0 9} \\
(0.013)\end{array}$ \\
\hline$I[t \geq 0] X$ TREND & - & $\begin{array}{c}\mathbf{- 1 . 2 8} \\
(0.165)\end{array}$ & - & $\begin{array}{c}0.09 \\
(0.460)\end{array}$ & & $\begin{array}{c}\mathbf{- 0 . 1 4} \\
(0.002)\end{array}$ & $\begin{array}{c}-2.72 \\
(5.236)\end{array}$ & $\begin{array}{c}-0.09 \\
(0.067)\end{array}$ & $\begin{array}{c}\mathbf{1 . 2 6} \\
(0.474)\end{array}$ & $\begin{array}{c}\mathbf{0 . 0 8} \\
(0.013)\end{array}$ & $\begin{array}{c}\mathbf{0 . 0 7} \\
(0.018)\end{array}$ \\
\hline \#Obs. & 18,851 & 18,851 & 18,851 & 18,851 & 19,279 & 19,277 & 28,912 & 28,912 & 19,279 & 28,912 & 28,912 \\
\hline Mean & 3.39 & 3.39 & 10.19 & 10.19 & 0.39 & 0.39 & 233.15 & 4.09 & 56.83 & 0.63 & 1.46 \\
\hline \multicolumn{12}{|c|}{ Sub-sample - excluding one period on each side of reform date } \\
\hline$I[t \geq 0]$ & $\begin{array}{c}-0.05 \\
(0.185)\end{array}$ & $\begin{array}{c}\mathbf{5 . 8 6} \\
(1.081)\end{array}$ & $\begin{array}{c}\mathbf{- 1 . 3 8} \\
(0.434)\end{array}$ & $\begin{array}{c}2.10 \\
(2.304)\end{array}$ & $\begin{array}{c}\mathbf{- 0 . 0 2} \\
(0.003)\end{array}$ & $\begin{array}{c}\mathbf{0 . 5 7} \\
(0.016)\end{array}$ & $\begin{array}{c}\mathbf{- 3 6 0 . 1 8} \\
(33.40)\end{array}$ & $\begin{array}{c}-4.65 \\
(0.390)\end{array}$ & $\begin{array}{c}-5.21 \\
(3.409)\end{array}$ & $\begin{array}{c}\mathbf{- 0 . 2 9} \\
(0.080)\end{array}$ & $\begin{array}{c}\mathbf{- 0 . 6 6} \\
(0.122)\end{array}$ \\
\hline TREND & $\begin{array}{l}- \\
-\end{array}$ & $\begin{array}{c}\mathbf{- 0 . 0 6} \\
(0.175)\end{array}$ & $\begin{array}{l}- \\
-\end{array}$ & $\begin{array}{c}0.24 \\
(0.373)\end{array}$ & $\begin{array}{l}- \\
-\end{array}$ & $\begin{array}{c}0.00 \\
(0.002)\end{array}$ & $\begin{array}{c}9.24 \\
(3.591)\end{array}$ & $\begin{array}{c}\mathbf{0 . 1 6} \\
(0.052)\end{array}$ & $\begin{array}{c}-0.28 \\
(0.550)\end{array}$ & $\begin{array}{c}\mathbf{0 . 0 3} \\
(0.013)\end{array}$ & $\begin{array}{c}0.02 \\
(0.019)\end{array}$ \\
\hline$I[t \geq 0] X$ TREND & - & $\begin{array}{c}\mathbf{- 0 . 9 3} \\
(0.247)\end{array}$ & - & $\begin{array}{c}-0.78 \\
(0.526)\end{array}$ & $\begin{array}{l}- \\
-\end{array}$ & $\begin{array}{c}\mathbf{- 0 . 0 9} \\
(0.003)\end{array}$ & $\begin{array}{c}\mathbf{6 5 . 3 8} \\
(7.075)\end{array}$ & $\begin{array}{c}\mathbf{0 . 7 5} \\
(0.085)\end{array}$ & $\begin{array}{c}\mathbf{1 . 8 5} \\
(0.777)\end{array}$ & $\begin{array}{c}\mathbf{0 . 0 8} \\
(0.018)\end{array}$ & $\begin{array}{c}\mathbf{0 . 1 0} \\
(0.028)\end{array}$ \\
\hline \# Obs. & 14,201 & 14,201 & 14,201 & 14,201 & 14,522 & 14,522 & 21,684 & 21,684 & 14,522 & 21,684 & 21,684 \\
\hline Mean & 2.63 & 2.63 & 8.66 & 8.66 & 0.34 & 0.34 & 273.39 & 5.16 & 54.91 & 0.85 & 2.10 \\
\hline
\end{tabular}

Note: Statistics Denmark, 20\% random sample. Bold indicates significance at 5\% level. S.E. in (), clustered on person ID, 'Mean' is the sample average of outcome in the pre-policy period. 
FIXED EFFECT ESTIMATION - INSULIN - CONSUMPTION OF OTHER DRUGS - LOW INCOME

\begin{tabular}{|c|c|c|c|c|c|c|c|c|c|c|c|}
\hline & $O O P / D D D$ & & $T P / D D D$ & & $O O P / T P$ & & $D D D$ & PRES & $D D D / P R E S$ & ESSENTIA & ESS ESS. \\
\hline & \multicolumn{11}{|c|}{ Full sample } \\
\hline \multirow[t]{2}{*}{$I[t \geq 0]$} & $\mathbf{0 . 3 3}$ & 4.04 & -0.51 & 0.044 & 0.05 & 0.67 & -315.81 & -4.34 & -4.23 & -0.75 & -1.19 \\
\hline & $(0.079)$ & $(0.296)$ & $(0.219)$ & $(0.832)$ & $(0.003)$ & $(0.008)$ & (17.11) & $(0.233)$ & $(1.350)$ & $(0.052)$ & $(0.078)$ \\
\hline \multirow[t]{2}{*}{ TREND } & - & -0.07 & - & -0.17 & - & -0.002 & 70.33 & 0.98 & 1.05 & 0.10 & 0.10 \\
\hline & - & $(0.049)$ & - & $(0.138)$ & - & $(0.001)$ & (3.373) & $(0.046)$ & $(0.224)$ & $(0.007)$ & $(0.012)$ \\
\hline \multirow[t]{2}{*}{$I[t \geq 0] X$ TREND } & - & -0.62 & - & 0.02 & - & -0.110 & 1.32 & -0.07 & 0.47 & 0.08 & 0.11 \\
\hline & - & $(0.070)$ & - & $(0.196)$ & - & $(0.002)$ & (4.003) & $(0.058)$ & $(0.319)$ & $(0.011)$ & $(0.018)$ \\
\hline \#Obs. & 23,729 & 23,729 & 23,729 & 23,729 & 23,959 & 23,959 & 28,912 & 28,912 & 23,959 & 28,912 & 28,912 \\
\hline \multirow[t]{2}{*}{ Mean } & 1.79 & 1.79 & 6.81 & 6.81 & 0.30 & 0.30 & 392.74 & 7.39 & 55.31 & 1.15 & 2.85 \\
\hline & & & Sub-sa & e - exclu & g one per & on each & le of refor & ate & & & \\
\hline \multirow[t]{2}{*}{$I[t \geq 0]$} & -0.16 & 1.70 & -0.66 & -0.33 & -0.03 & 0.32 & -248.65 & -3.50 & -1.41 & -0.28 & -0.63 \\
\hline & $(0.075)$ & $(0.412)$ & $(0.245)$ & (1.299) & $(0.003)$ & $(0.012)$ & $(26.23)$ & $(0.356)$ & (2.178) & $(0.074)$ & $(0.120)$ \\
\hline \multirow[t]{2}{*}{ TREND } & - & -0.03 & - & 0.03 & - & -0.001 & 5.59 & 0.09 & -0.06 & 0.06 & 0.03 \\
\hline & - & (0.066) & - & $(0.210)$ & - & $(0.002)$ & (3.149) & $(0.044)$ & $(0.351)$ & $(0.011)$ & $(0.018)$ \\
\hline \multirow[t]{2}{*}{$I[t \geq 0] X$ TREND } & - & -0.29 & - & -0.08 & - & -0.06 & 48.07 & 0.59 & 1.02 & 0.05 & 0.09 \\
\hline & - & (0.094) & - & $(0.297)$ & - & $(0.003)$ & (5.570) & $(0.076)$ & $(0.497)$ & (0.016) & $(0.027)$ \\
\hline \#Obs. & 17,869 & 17,869 & 17,869 & 17,869 & 18,041 & 18,041 & 21,684 & 21,684 & 18,041 & 21,684 & 21,684 \\
\hline Mean & 1.83 & 1.83 & 6.86 & 6.86 & 0.30 & 0.30 & 350.29 & 6.75 & 54.40 & 1.11 & 2.79 \\
\hline
\end{tabular}

Note: Statistics Denmark, 20\% random sample. Bold indicates significance at 5\% level. S.E. in (), clustered on person ID, 'Mean' is the sample average of outcome in the pre-policy period. 


\section{Economics Working Paper}

2009-18: Christian Bjørnskov and Martin Paldam: The spirits of capitalism and socialism. A cross-country study of ideology

2010-1: $\quad$ Laurent Callot and Martin Paldam: Natural funnel asymmetries. A simulation analysis of the three basic tools of meta analysis

2010-2: $\quad$ Allan Sørensen: Welfare Effects of Trade Liberalization with Intra-industry Reallocations: The Importance of Preferences and Market Failures

2010-3: $\quad$ Marianne Simonsen, Lars Skipper and Niels Skipper: Price Sensitivity of Demand for Prescription Drugs: Exploiting a Regression Kink Design

2010-4: $\quad$ Torben M. Andersen and Allan Sørensen: Product market integration, rents and wage inequality

2010-5: John Kennes and Daniel le Maire: Coordination Frictions and Job Heterogeneity: A Discrete Time Analysis

2010-6: $\quad$ Philipp J.H. Schröder and Allan Sørensen: The Theoretical Equivalent of Empirically Measurable Exporter Productivity when Firms are Heterogeneous

2010-7: $\quad$ Nabanita Datta Gupta and Marianne Simonsen: Effects of Universal Child Care Participation on Pre-teen Skills and Risky Behaviors

2010-8: $\quad$ Olaf Posch and Timo Trimborn: Numerical solution of continuous-time DSGE models under Poisson uncertainty

2010-9: Torben M. Andersen and Allan Sørensen: Globalization, tax distortions and public sector retrenchment

2010-10: $\quad$ Philipp J.H. Schröder and Allan Sørensen: Ad valorem versus unit taxes: Monopolistic competition, heterogeneous firms, and intra-industry reallocations

2010-11: Søren Leth-Petersen and Niels Skipper: Income and the use of prescription drugs for near retirement individuals

2010-12: Niels Skipper: On Utilization and Stockpiling of Prescription Drugs when Copayments Increase: Heterogeneity across Types of Drugs 